NBER WORKING PAPER SERIES

ON THE POLITICAL ECONOMY OF EDUCATIONAL VOUCHERS

\author{
Dennis N. Epple \\ Richard Romano \\ Working Paper 17986 \\ http://www.nber.org/papers/w17986
NATIONAL BUREAU OF ECONOMIC RESEARCH
1050 Massachusetts Avenue
Cambridge, MA 02138
April 2012

The authors thank Stephen Coate and two anonymous referees for comments, but we retain responsibility for errors. The views expressed herein are those of the authors and do not necessarily reflect the views of the National Bureau of Economic Research.

NBER working papers are circulated for discussion and comment purposes. They have not been peerreviewed or been subject to the review by the NBER Board of Directors that accompanies official NBER publications.

(C) 2012 by Dennis N. Epple and Richard Romano. All rights reserved. Short sections of text, not to exceed two paragraphs, may be quoted without explicit permission provided that full credit, including (c) notice, is given to the source. 
On The Political Economy Of Educational Vouchers

Dennis N. Epple and Richard Romano

NBER Working Paper No. 17986

April 2012, Revised June 2013

JEL No. D72,H44,I22

\begin{abstract}
$\underline{\text { ABSTRACT }}$
Two significant challenges hamper analyses of the collective choice of educational vouchers. One is the multi-dimensional choice set arising from the interdependence of the voucher, public education spending, and taxation. Second, even absent a voucher, preferences over public spending are not single-peaked; a middling level of public school spending may be less attractive to a household than either high public school spending or private education coupled with low public spending. We show that Besley and Coate's (1997) representative democracy model provides a viable approach to overcome these hurdles. We provide a complete characterization of equilibria with an endogenous voucher. A voucher is adopted in political equilibrium provided the coefficient of variation of income is sufficiently small. We undertake a parallel quantitative analysis. We find that no voucher arises in equilibrium for the U.S. income distribution, which exhibits too much heterogeneity. For tighter income distributions, including those in Douglas County, Colorado (where a voucher was recently adopted) and in Denmark (which has a national voucher program) our model predicts a positive voucher. Public support for a not-too-large voucher arises because the cross subsidy to public school expenditure from those switching to private schools outweighs the subsidy to those who attend private school in the absence of a voucher.
\end{abstract}

\author{
Dennis N. Epple \\ Tepper School of Business \\ Carnegie Mellon University \\ Posner Hall, Room 257B \\ Pittsburgh, PA 15213 \\ and NBER \\ epple@cmu.edu \\ Richard Romano \\ University of Florida \\ richard.romano@cba.ufl.edu
}




\section{On the Political Economy of Educational Vouchers}

\section{Introduction}

Vouchers that can be used to finance education at private schools are frequently advocated and regularly proposed as a policy to improve education in the U.S. With a few exceptions, these proposals fail politically. Critics of vouchers decry the loss of funding for public school students that would arise by public educational monies being diverted to finance vouchers. Without the support of households that would remain in public schools, voucher proposals are unlikely to be politically feasible. As investigation by other researchers has shown, however, vouchers below per student public expenditure might increase that expenditure as students take up vouchers and exit the public sector in spite of the subsidy to students initially in private schools. We investigate the public choice equilibrium that permits vouchers in light of this possibility.

Our analysis builds on the literature focused on the fiscal effects of vouchers. ${ }^{1}$ Ireland (1990) provides the first formal model of public-private provision of a good with a voucher as a centerpiece. Ireland showed theoretically that some policy vectors Pareto-dominate others, in particular that expenditure per public school student might rise with a voucher for fixed tax system. In addition to being the first to make this observation (to our knowledge), his framework has been the point of departure for further research. Rangazas (1995) identifies three effects of a voucher on majority choice of public expenditure. A voter with a child in public school faces a lower tax price of increasing public expenditure because the voucher induces some students to switch from public to private schools. Thus, when the voucher is less than per student public expenditure, those that switch schools cross-subsidize students in public schools. Of course, tax revenues must also finance the voucher including students that would

\footnotetext{
${ }^{1}$ Other research on vouchers is discussed below.
} 
attend private school with no voucher. In addition to the latter two effects, the median voter's wealth would decline with a positive voucher as relatively wealthy households take up the voucher and exit public schools. Assuming voters ignore the effect of vouchers on school sector choice when voting for public expenditure, Rangazas employs parameter estimates to conclude the net effect of a voucher would be to increase support for public expenditure. Like Ireland, Rangazas does not examine equilibrium determination of a voucher. The most closely related paper to ours is Hoyt and Lee (1998). They also investigate political support for vouchers in a model with the same technological elements as we do, but differ with respect to their analysis of equilibrium. Most of their analysis holds constant public expenditure. They show that vouchers can lower tax rates given public expenditure, which would imply a Pareto improvement and thus political support for a voucher. Their analysis of an endogenous voucher assumes two stages, with the voucher determined first followed by median preferred choice of public expenditure (with tax that balances the budget). They provide conditions such that a positive voucher would be majority preferred to no voucher.

Our contribution is to provide a complete equilibrium analysis, including a demonstration of existence computationally, and to examine equilibrium outcomes in a realistically calibrated model. While the analysis abstracts from factors that might affect public choice of a voucher (e.g., effects on school productivities), it clarifies the pure fiscal incentives in the context of the "standard model."

Finding a public-choice equilibrium with vouchers is nontrivial because the relevant policy vector is a triplet: the tax rate, per student public expenditure, and the amount of the voucher. Using the government budget constraint, the policy vector can be reduced to two variables, but the standard multidimensional voting problem (Plott, 1967) precludes existence of

\footnotetext{
${ }^{2}$ Other factors that might affect public choice of a voucher are discussed in Section 5.2.
} 
a majority choice equilibrium over all feasible policy vectors. We resolve this problem by using the representative democracy model of Besley and Coate (1997). ${ }^{3}$ Voters elect a member of the population anticipating that the office holder will implement his/her preferred policy vector, which is known. The implied restriction on equilibrium policies implies existence of a Condorcet winner in our model and a population member with such preferences is elected. Our analysis illustrates the power of the Besley-Coate model in finding a public-choice equilibrium, which we view as another contribution of the paper.

The theoretical analysis identifies conditions under which the model predicts a positive voucher. For parameters such that the elected office holder sends his/her child to public school, a simple condition that tracks the earlier literature must be satisfied. The tax saving from students that switch from public to private schools with the introduction of a voucher must exceed the tax cost of subsidizing those students that would choose private education with no voucher. The tax saving is relatively large if public expenditure is high and a voucher would induce significant switching to private schools, while the tax cost is relatively high if private school patronage is substantial with no voucher. We provide a theoretical argument that the coefficient of variation in the wealth level of an economy is the relevant statistic determining whether a voucher is politically supported.

We then turn to a computational analysis calibrated to the data to investigate further when a voucher might arise. The computational analysis serves several purposes. First, it provides nontrivial examples where the equilibrium we study exists. Second, it illustrates the features of such equilibria. Third, it shows that the model predicts a positive voucher with low coefficient of variation of wealth. With the income distribution calibrated to the U.S. population or to several state income distributions, no voucher arises in equilibrium. With the income

\footnotetext{
${ }^{3}$ See also Osborne and Slivinski (1996).
} 
distribution calibrated to that in Douglas County, a district in the Denver, Colorado MSA, where a voucher was recently unanimously approved by the locally elected district school board, a voucher does arise in equilibrium. The equilibrium with a voucher is Pareto improving relative to equilibrium with no voucher allowed. A lower tax rate and higher per student expenditure arise with a voucher. While Douglas County is wealthy relative to the U.S., it is a combination of lower variance and higher mean income in Douglas County that is relevant to finding a positive voucher in equilibrium. Calibrating to the low-variance national income of Denmark, our model also predicts a substantial voucher as characterizes Denmark. While these examples are not contrived, we do not claim our model explains the empirical adoption and rejection of vouchers. Non-fiscal factors from which we abstract are surely relevant. We do believe that our analysis clarifies impacts on the fiscal tradeoff relevant to voucher adoption.

For realistic parameters, equilibrium has the "ends against the middle" property that arises in Epple and Romano (1996a,1996b). Whether or not a voucher is chosen, a coalition of the poorest voters whose children attend public school and rich voters that send their children to private school prefer lower tax and public expenditure, balanced by an equal-sized coalition of middle-income households with children in public school that advocate the opposite. ${ }^{4}$ In the computational analysis, we show how voting coalitions would vary in elections pitting the winning candidate for office against candidates with differing incomes and thus preferred policies.

Other research on vouchers bears mention but is a bit more distant. Chen and West (2000) and Bearse, Cardak, Glomm, and Ravikumar (2009) consider majority approval of voucher regimes that provide every student with a voucher, i.e., with no distinct public alternative available. Voucher programs that do not permit a public alternative have diminished political

\footnotetext{
${ }^{4}$ The ends-against-the-middle property of voting coalitions also arises in Rangazas's and Hoyt and Lee's analyses.
} 
support because the cross subsidy (discussed above) to public school students from those that switch to private schools disappears. These papers both then consider political support for "targeted vouchers" that vary with income. Epple and Romano (2008) examine voucher design that would eliminate cream skimming of classmates by private schools when students differ by ability and educational peer effects are present. They provide a fiscally neutral targeted voucher design that would eliminate incentives of private schools to cream skim high-ability students and would lead to (near) Paretian gains if competition for students improves outcomes. ${ }^{5}$ The present paper focuses on voucher programs that are non-targeted and permit expenditure per pupil in public schools to differ from the amount of the voucher, as are frequently proposed. ${ }^{6}$

Section 2 presents the model and some preliminary results. Section 3 develops the main theoretical results. Section 4 provides the computational analysis of equilibrium. Section 5 discusses issues relevant to vouchers from which our analysis abstracts. Section 6 summarizes. An appendix contains much of the technical analysis.

\section{The Model and Preliminary Results}

We refer to the decision makers in the economy as "households" or "voters." A household has an endowed income $y$, a child in school, and utility function $U(x, q)$, where $x$ is numeraire consumption and $q$ is the quality of education. Educational quality is measured by per student expenditure in the student's school. $U$ is increasing, twice differentiable, and quasiconcave in $(x, q)$, and satisfies the standard Inada property. Ordinary demand for educational

\footnotetext{
${ }^{5}$ Nechyba $(1999,2000)$ examines the effects on educational quality of inter-district household mobility of various voucher designs. See Epple and Romano (2012) for discussion of more models of vouchers and other references.

${ }^{6}$ As one example, the California state-wide voucher proposal (Proposition 38) that was defeated by referendum, supported by only $30 \%$ of the population, would have provided a $\$ 4,000$ voucher, one-half the per student public expenditure there. The Douglas County School District voucher equals $75 \%$ of state funding, which is about $55 \%$ of per student public funding. We do not mean to suggest that voucher programs fit one model. Many proposals are means tested and/or targeted to students at failing schools.
} 
quality is normal. The population of households is characterized by a continuous distribution on income $F(y)$, with density $f(y)$, positive on $\left[y_{\min }, y_{\max }\right]$. Denote mean income $Y$.

Households will choose to send their child to a public or private school. Let g denote expenditure per student in the public sector, which is the same for every student attending a public school. Public finance is by a proportional income tax denoted t. Utility of household y if their child attends a public school is then: $U^{P}=U(y(1-t), g) .^{7}$ Relevant to household preferences over $(t, g)$, we make the following assumption:

$$
\left.\frac{\mathrm{dt}}{\mathrm{dg}}\right|_{\mathrm{U}^{\mathrm{P}}=\text { const. }}=\frac{\mathrm{U}_{\mathrm{q}} / \mathrm{U}_{\mathrm{x}}}{\mathrm{y}} \text { increa ses with } \mathrm{y} .
$$

The single-crossing assumption regarding voter indifference curves drawn in the $(g, t)$ plane means that the marginal willingness to bear a tax increase for higher $g$ rises with income; indifference curves steepen as income rises. This implies that, among those that choose public schools, higher income voters support higher educational expenditure despite their higher tax price. Empirical evidence supports this assumption. ${ }^{8}$

Let $\mathrm{v} \geq 0$ denote a voucher provided to any household that attends private school. Policy requires that all of $v$ is spent on education if private school is attended. Private schooling is competitively provided with constant returns to scale. Thus a household that sends its child to private schools obtains utility: $U^{R}=\operatorname{MAX}_{s \geq 0} U(y(1-t)-s, v+s)$, where $s$ is supplemental expenditure above the voucher. Denote the solution to the latter optimization $s^{*}(t, v, y)$.

\footnotetext{
${ }^{7}$ By "household y," we mean household with income y. As well, we sometimes refer to "voter y."

${ }^{8}$ Early empirical evidence is discussed in Epple and Romano (1996a). Epple and Sieg (1999) and Brunner and Ross (forthcoming) provide alternative evidence supporting such an assumption. An appendix to Epple and Romano (1996a) shows that (A1) will be satisfied if the income elasticity of demand for educational quality is higher than the absolute value of the price elasticity of demand, provided the expenditure share on education is not too large. This theoretical characterization of the assumption derives from Kenny (1978).
} 
For given policy $(t, v, g)$ with $g>v$, there will exist a threshold income value $\mathrm{y}_{\mathrm{T}}(\mathrm{t}, \mathrm{v}, \mathrm{g})>0$ satisfying $U^{P}=U^{R}$, such that households with income $y>(<) y_{T}$ will choose private (public) education. ${ }^{9}$ Realistic parameters and policies that have $\mathrm{g}>0$ will result in consumption of both the public and private alternative. To avoid a tedious presentation, we then assume:

(A2) Policy vectors with $\mathrm{g}>0$ have $\mathrm{y}_{\mathrm{T}} \in\left(\mathrm{y}_{\min }, \mathrm{y}_{\max }\right)$, thus consumption of both public and private education.

Simple comparative static properties are:

(1) $\quad \frac{\partial \mathrm{y}_{\mathrm{T}}}{\partial \mathrm{t}}>0 ; \frac{\partial \mathrm{y}_{\mathrm{T}}}{\partial \mathrm{g}}>0 ;$ and $\frac{\partial \mathrm{y}_{\mathrm{T}}}{\partial \mathrm{v}}<0$

The income of the indifferent household rises if disposable income decreases or if the quality of public education rises. Increasing the voucher for private education has the opposite effect. If $g$ $\leq v$ (including the case of $v=0$ ), then specify that $y_{\top}=0$, consistent with the fact that no household would prefer the public alternative.

The government budget must be balanced:

$$
\mathrm{tY}=\mathrm{F}\left(\mathrm{y}_{\mathrm{T}}\right) \mathrm{g}+\left(1-\mathrm{F}\left(\mathrm{y}_{\mathrm{T}}\right)\right) \mathrm{v}
$$

Public choice of the policy vector is modeled using a version of Besley and Coate's (1997) representative democracy model. Our model has the technical difference that we assume a continuum of voters, while Besley and Coate assume a discrete distribution of voter types. The central assumption in Besley and Coate is that voters elect a policy maker correctly anticipating implementation of the policy maker's preferred policy, which is known. In addition to the latter, assume: (A3) Any voter can become a candidate at 0 cost. $^{10}$ (A4) If no candidate enters the race or if a positive measure of votes fails to materialize, then a relatively lousy policy

\footnotetext{
${ }^{9}$ This is straightforward to confirm and "well known," so we omit proof. See Rangazas (1995).

${ }^{10}$ Besley and Coate focus on cases with positive entry cost, though consider cases with vanishingly small entry cost.
} 
$p^{0}$ is implemented, which is worse for everyone than a positive measure of policies $p \in \mathrm{P}^{*} .^{11}$

(A5) Voting is costless and voters maximize their utility in Nash equilibrium, but never choose weakly dominated voting strategies. (A6) Assuming entry into the election, a candidate receiving a plurality of votes is elected, with equal probability tie breaking if multiple candidates tie for the win.

Equilibrium has rational expectations with the following sequence of choices. First, households decide whether to become candidates. If no one enters, the lousy policy is implemented (that satisfies balanced budget for optimal household choices). Otherwise, a candidate is elected as described, whom we refer to as the superintendent. The superintendent then implements his preferred policy vector, which must be consistent with the next stage. Last, households optimize, choosing the public or private alternative, the latter with optimal supplement, and the government budget balances. When households optimize, they take as given the balanced budget policy vector, this consistent with the continuum of households and thus inability to unilaterally affect the policy outcome. ${ }^{12}$

We examine cases where there is a Condorcet winner among the preferred policies of households, which holds in our computational model. Let $\left(t^{*}(y), v^{*}(y), g^{*}(y)\right)$ denote the preferred policy vector of household y, which we assume to be unique. It satisfies:

$$
\begin{aligned}
& \operatorname{Max}_{t \geq 0, v \geq 0, g \geq 0}\left[\operatorname{Max}\left\{U^{P}, U^{R}\right\}\right] \\
& \text { s.t. (2) and } y_{T}=y_{T}(t, v, g) .
\end{aligned}
$$

Let $p=(t, v, g)$ denote a policy vector, $p^{*}(y)=\left(t^{*}(y), v^{*}(y), g^{*}(y)\right)$ a preferred policy vector, and $\mathrm{P}^{*}=\left\{\mathrm{p}^{*}(\mathrm{y}) \in \mathrm{R}_{+}^{3} \mid \mathrm{f}(\mathrm{y})>0\right\}$ the set of preferred policy vectors. Given the continuum of types,

\footnotetext{
${ }^{11}$ With no one in leadership, public policy is not as well managed as if some candidates are elected.

${ }^{12}$ It is equivalent to require that the superintendent sets any two variables of the $(t, v, g)$ policy vector, with the other determined in the last stage under rational expectations. These are equivalent because households are "atomistic" policy takers.
} 
a Condorcet winner is a policy $\mathrm{p}^{\mathrm{w}} \in \mathrm{P}^{*}$ that is weakly preferred by at least one-half the measure of all voters $\mathrm{y}$ over all alternative policies $\mathrm{p}^{*} \in \mathrm{P}^{*}$. Given existence of a $\mathrm{p}^{\mathrm{w}}$, let $\mathrm{y}^{\mathrm{w}}$ denote a voter that prefers $p^{w}$; i.e., satisfies $p^{w}=p^{*}\left(y^{w}\right)$.

Proposition 0 is an adaptation of Besley and Coate's Corollary 1 to our problem with a continuum of voters:

Proposition 0 (Besley and Coate): Assuming a Condorcet winner $p^{w}$ : (i) a single candidate equilibrium with candidate $y^{w}$ exists, with that candidate elected; and (ii) a single candidate equilibrium must have a $y^{w}$ elected.

The formal proof closely follows Besley and Coate, though we provide a proof in the appendix for convenience. Intuitively, entry by just a $\mathrm{y}^{\mathrm{w}}$ will lead to his election, to avoid the lousy alternative if no one is elected. Entry by household with alternative policy preference would induce entry by $a \mathrm{y}^{\mathrm{w}}$, who would defeat the former and thus get his preferred policy.

Motivated by Proposition 0, we henceforth focus on equilibria with a policy vector that is a Condorcet winner among preferred policies. While existence holds under Proposition 0, uniqueness of political equilibrium is not implied, as Proposition 0 does not rule out multiple candidate equilibria. The appendix provides a modified two-party version of the model that also has uniqueness of the Condorcet winner as the policy outcome.

\section{Theoretical Results}

Assuming equilibrium exists, we develop a series of results concerning the character of equilibria that might arise, including when equilibrium has a voucher.

3.1 Properties of the Policy Vector. We begin with:

Proposition 1. If the superintendent chooses private schooling, then $t^{*}=v^{*}=g^{*}=0$ and the superintendent's income exceeds the mean. 
Proofs omitted from the text are provided in Part B of the Appendix. To understand Proposition 1, observe that only superintendents with income exceeding the mean might choose private school since lower income households benefit from the tax financing of public provision. Given income above the mean and choice of private schooling, facing a tax price exceeding one and indifference to the quality of public schooling imply $t=g=v=0$ is preferred. Such equilibria are uninteresting and never arise in our computational analysis. Hence, we consider further only equilibria where a public sector arises $(g>v)$. Now consider the policy choice of a superintendent y that would choose public education.

Proposition 2. A superintendent who selects public school chooses $(t, v)$ that solves the problem:

$$
\mathrm{MIN}_{\mathrm{t} \geq 0, \mathrm{v} \geq 0} \mathrm{t}
$$

$$
\text { s.t. } \mathrm{tY}=\mathrm{F}\left(\mathrm{y}_{\mathrm{T}}\left(\mathrm{t}, \mathrm{v}, \mathrm{g}^{*}\right)\right) \mathrm{g}^{*}+\left[1-\mathrm{F}\left(\mathrm{y}_{\mathrm{T}}\left(\mathrm{t}, \mathrm{v}, \mathrm{g}^{*}\right)\right)\right] \mathrm{v} \text {, }
$$

where $g^{*}$ is the superintendent's preferred $g$.

Since the superintendent's utility is given by $U\left(y(1-t), g^{*}\right)$, his objective in choosing $(t, v)$ reduces to minimizing the equilibrium tax rate, which solves (4). Proposition 2 is a version of the result that is at the heart of the earlier discussed research on vouchers of Ireland (1990), Rangazas (1995), and Hoyt and Lee (1998). The incentive of households using public schools to provide a voucher is to increase the cross subsidization of households that select private schools while still having to pay taxes. This logic applies, of course to any household choosing public school:

Corollary 1. Given any equilibrium g that would be chosen by a superintendent, all households that choose public education prefer (t,v) satisfying problem (4).

Toward providing a complete description of equilibrium with public provision, let $\mathrm{t}^{\mathrm{M}}(\mathrm{g})$ denote the solution to (4) for $t$ for any $g \geq 0$. Let $v^{M}(g)$ denote the solution for $v$. Also, define indifference curves of public school patrons, $\mathrm{U}(\mathrm{y}(1-\mathrm{t}), \mathrm{g})=$ const., in the $(\mathrm{g}, \mathrm{t})$ plane (see Figure 1 
for an example). These indifference curves have positive slope as described in (A1) and are steeper for higher income superintendents that choose public schooling, also by (A1). The next result helps to clarify the determination of equilibrium as well as its properties.

Lemma 1. Assuming the superintendent with income y chooses public school, equilibrium $\left(t^{*}, g^{*}\right)$ occurs at a tangency between an indifference curve $U(y(1-t), g)=$ const. and the $t^{M}(g)$ locus, with equilibrium $v^{*}=v^{M}\left(g^{*}\right)$.

Lemma 1 follows from the fact that the superintendent maximizes utility given public attendance, choosing policy vector that satisfies (4); i.e., $\left(\mathrm{t}^{*}, \mathrm{v}^{*}, \mathrm{~g}^{*}\right) \equiv\left(\mathrm{t}^{\mathrm{M}}\left(\mathrm{g}^{*}\right), \mathrm{v}^{\mathrm{M}}\left(\mathrm{g}^{*}\right), \mathrm{g}^{*}\right)$. Figure 1 depicts the choice of $\left(t^{*}, g^{*}\right)$ by the superintendent. As one moves along the $t^{\mathrm{M}}(\mathrm{g})$ locus in Figure $1, v$ varies according to $v^{\mathrm{M}}(\mathrm{g})$. But the implied voucher is not directly relevant to the superintendent. Thus, one can depict the superintendent's optimum $(t, g)$ as in Figure 1 , with the voucher level suppressed. Note that Lemma 1 implies it must be that $d t^{\mathrm{M}} / \mathrm{dg}>0$ at the equilibrium point. Using (A1), we have:

Corollary 2. Among those choosing public education, their preferred $g$ and $t$ are strictly increasing in $y ; g^{* \prime}(y)>0$ and $t^{* \prime}(y)>0$.

To see Corollary 2 holds, draw a steeper indifference curve through $\left(\mathrm{g}^{*}, \mathrm{t}^{*}\right)$ in Figure 1 for a household with higher income (but still choosing public schooling). Such a household would prefer higher $\mathrm{g}$ on $\mathrm{t}^{\mathrm{M}}(\mathrm{g})$, in spite of the need for a higher tax. These results will help to clarify the voting coalitions that characterize equilibrium.

3.2 The Equilibrium Voting Coalition: Ends-Against-the-Middle. Let $y^{w}$ denote the income of the superintendent elected in equilibrium. A necessary condition for a global equilibrium is that the allocation is also a "local equilibrium" in the following sense. A household with income infinitesimally higher or lower than $\mathrm{y}^{\mathrm{w}}$ could not defeat household $\mathrm{y}^{\mathrm{w}}$, i.e., could not prefer a policy that would garner a strict majority relative to household $\mathrm{y}^{\mathrm{w}}$ s preferred policy. We show 
next that the requirement that equilibrium is a local equilibrium implies it satisfies the "ends against the middle" property given (A1) and a condition we now develop.

Let:

$$
\mathrm{y}_{\mathrm{T}}^{\mathrm{e}} \equiv \mathrm{y}_{\mathrm{T}}\left(\mathrm{t}^{*}\left(\mathrm{y}^{\mathrm{w}}\right), \mathrm{v}^{*}\left(\mathrm{y}^{\mathrm{w}}\right), \mathrm{g}^{*}\left(\mathrm{y}^{\mathrm{w}}\right)\right)
$$

which equals the threshold income in equilibrium delineating those that consume public and private education. Equilibrium utility for those that consume private education is given by: $\left.\mathrm{U}=\mathrm{U}\left(\mathrm{y}\left(1-\mathrm{t}^{*}\left(\mathrm{y}^{\mathrm{w}}\right)\right)-\mathrm{s}^{*}(\cdot), \mathrm{v}^{*}\left(\mathrm{y}^{\mathrm{w}}\right)\right)+\mathrm{s}^{*}(\cdot)\right)$, where private school supplement $\mathrm{s}^{*}$ is evaluated at the equilibrium policy vector. The additional condition for the ends-against-the-middle property of equilibrium is:

$$
\frac{\mathrm{dU}}{\mathrm{dy} \mathrm{w}^{\mathrm{w}}}=-\mathrm{U}_{\mathrm{x}} \mathrm{yt}^{* \prime}+\mathrm{U}_{\mathrm{q}} \mathrm{v}^{* \prime}<0 \text { for all } \mathrm{y}>\mathrm{y}_{\mathrm{T}}^{\mathrm{e}},
$$

where the arguments of the functions are evaluated at equilibrium values. (Recall that $x$ denotes the numeraire and q school quality.) We know from Corollary 2 that $\mathrm{t}^{* \prime}>0$ in an equilibrium with a public sector, implying $\mathrm{v}^{* \prime} \leq 0$ is a sufficient condition for the assumption to hold. ${ }^{13}$ Assumption (A7) implies those in private schools would vote for a candidate with lower income than the superintendent, this driven at least in part by such a candidate's preference for a lower tax.

Proposition 3: Ends-Against-the-Middle. Under (A1), (A2), and (A7), an equilibrium with superintendent $y^{w}$ that chooses public education must satisfy:

(i) $\int_{y^{w}}^{y_{T}^{e}} f(y) d y=.5$; and

\footnotetext{
${ }^{13}$ If $v^{*}=0$ in the vicinity of equilibrium, then the condition is satisfied. When $v^{*}=0$, the ends-against-themiddle result is particularly analogous to the case of Epple and Romano (1996a) where vouchers are not a policy choice. This case is, however, of less interest since no voucher arises in equilibrium. Corollary 1 implies $v^{*}(y)=v^{M}\left(g^{*}(y)\right)$ among superintendents that would choose public school. We find in our computational mode that $v^{\mathrm{M}}$ is increasing when $\mathrm{v}^{\mathrm{M}}$ is positive. (A7) then needs to be verified computationally. We find (A7) is satisfied in our computations.
} 
(ii) households with $\mathrm{y} \in\left(\mathrm{y}^{\mathrm{w}}, \mathrm{y}_{\mathrm{T}}^{\mathrm{e}}\right)$ prefer a superintendent with slightly higher $\mathrm{y}$ than $\mathrm{y}^{\mathrm{w}}$; and those

with incomes $y<y^{w}$ and $y>y_{\mathrm{T}}^{\mathrm{e}}$ prefer a superintendent with slightly lower $y$.

An intuitive perspective on Proposition 3 begins with Part (ii). Among households choosing public school, those with income higher (lower) than $\mathrm{y}^{\mathrm{w}}$ prefer higher (lower) g along the $t^{\mathrm{M}}(\mathrm{g})$ locus by $(\mathrm{A} 1)$. Thus, they favor (respectively) superintendents with higher (lower) income who share the same preference. The households in private school all prefer a lower $t$ along the $\mathrm{t}^{\mathrm{M}}(\mathrm{g})$ locus by $(\mathrm{A} 7)$, though this might imply a lower voucher. Since equilibrium requires balanced coalitions of voters, Part (i) of Proposition 3 must be satisfied. Thus, such an equilibrium has superintendent with income below the median and a coalition of rich and poor preferring lower tax and public expenditure on education opposed by middle-income types that favor higher tax and public expenditure. ${ }^{14}$

3.3 Conditions for a Positive Voucher. To consider the issue as to when a positive voucher arises in equilibrium, form the Lagrangian function for problem (4) and examine its solution:

$$
\mathrm{L}=\mathrm{t}+\lambda \cdot\left\{\mathrm{tY}-\left[\left(1-\mathrm{F}\left(\mathrm{y}_{\mathrm{T}}\left(\mathrm{t}, \mathrm{v}, \mathrm{g}^{*}\right)\right) \mathrm{v}+\mathrm{F}\left(\mathrm{y}_{\mathrm{T}}\left(\mathrm{t}, \mathrm{v}, \mathrm{g}^{*}\right)\right) \mathrm{g}^{*}\right]\right\}\right.
$$

Along with the constraint in (4), the Kuhn-Tucker conditions are:

$$
\mathrm{L}_{\mathrm{t}}=1+\lambda\left[\mathrm{Y}+\left(\mathrm{v}-\mathrm{g}^{*}\right) \mathrm{f}\left(\mathrm{y}_{\mathrm{T}}\right) \frac{\partial \mathrm{y}_{\mathrm{T}}}{\partial \mathrm{t}}\right]=0 ; \text { and }
$$

$$
\mathrm{L}_{\mathrm{v}}=-\lambda\left[1-\mathrm{F}\left(\mathrm{y}_{\mathrm{T}}\right)+\left(\mathrm{g}^{*}-\mathrm{v}\right) \mathrm{f}\left(\mathrm{y}_{\mathrm{T}}\right) \frac{\partial \mathrm{y}_{\mathrm{T}}}{\partial \mathrm{v}}\right] \geq 0
$$

$\mathrm{L}_{\mathrm{v}} \cdot \mathrm{v}=0$

$\mathrm{v} \geq 0$.

\footnotetext{
${ }^{14}$ If the equilibrium has no voucher, then it is generically equivalent to the equilibrium if no voucher is allowed. This is in spite of the fact that some households might prefer a voucher if they were elected. The reason is that the equilibrium conditions include satisfaction of the local equilibrium conditions and the feasible $(\mathrm{t}, \mathrm{g})$ pairs - given by the $\mathrm{t}^{\mathrm{M}}(\mathrm{g})$ locus - will be the same generically in the vicinity of the equilibrium as when no voucher is allowed. The exception is when the superintendent is just indifferent to providing a voucher, but this arises with probability 0 .
} 
We specify (7a) with equality since t $>0$ must arise in an equilibrium with a public sector. The issue is whether $v=0$ is consistent with the set of conditions, in particular those in (7b). Since the minimand in (4) obviously decreases with $Y$ (mean income), we know by the usual Envelope Theorem argument that $\lambda<0$. Using this and setting $v=0$, it follows from the top line of $(7 b)$ that $\mathrm{v}$ is positive if:

$$
\begin{aligned}
1-\mathrm{F}\left(\mathrm{y}_{\mathrm{T}}\right)+\mathrm{g}^{*} \mathrm{f}\left(\mathrm{y}_{\mathrm{T}}\right) \frac{\partial \mathrm{y}_{\mathrm{T}}}{\partial \mathrm{v}} & <0 \text { given } \mathrm{v}=0, \mathrm{y}_{\mathrm{T}}=\mathrm{y}_{\mathrm{T}}\left(\mathrm{t}, 0, \mathrm{~g}^{*}\right), \text { and } \\
\text { t satisfying } \mathrm{tY} & =\mathrm{F}\left(\mathrm{y}_{\mathrm{T}}\right) \mathrm{g}^{*} .
\end{aligned}
$$

We have:

Proposition 4A: In an equilibrium with a public sector, condition (8) is sufficient for a positive voucher. If, also, the superintendent's optimization problem has a unique local optimum, then (8) is also a necessary condition.

The sufficiency of (8) has been shown. The necessity of (8) follows since, absent (8), no voucher would be a local optimum. If there is only one local optimum, then this would as well be the global optimum. Appendix B provides the condition for uniqueness of the local optimum.

To interpret (8), suppressing arguments, note that $f \cdot \partial y_{T} / \partial v=-\partial[1-F] / \partial v$; implying (8) can be written: $g^{*} \cdot \partial[1-F] / \partial v>1-F$. The trade off in introducing a voucher is captured by the latter inequality. The left-hand side is the marginal benefit of increasing the voucher from 0 to public school students and so for the superintendent, which equals the cost saving of $\mathrm{g}^{*}$ per student multiplied by the number of students who are induced to switch to private schools. The right-hand side is the marginal cost, equal to the number of students attending private schools with no voucher who are then "unnecessarily" supplemented.

Of primary interest is when the model predicts a voucher. Theoretically, whether condition (8) is satisfied depends on the income distribution and the utility function. Suppose 
that the utility function is known. The local properties of the income distribution at $y_{\top}$ are clearly relevant, but finding the values of $\mathrm{y}_{\top}$ and $\mathrm{g}^{*}$ to evaluate (8) require knowledge of the whole distribution to determine the identity of the superintendent who chooses $g^{*}$ and $t$. The theoretical and computational analysis below examines when we might expect the condition to be satisfied.

Investigating the model's predictions as to when a voucher would arise empirically is another matter. The question of interest here is, beginning in an equilibrium where a voucher is prohibited, what would need to be determined to predict a voucher if the prohibition is relaxed? One can motivate this question by changes in beliefs in the economy about the legal feasibility of a voucher or simply a realization by voters that a voucher might be optimal. Relevant to considering this is that the elected superintendent under the presumption that a voucher is infeasible would be a different individual than the elected superintendent allowing a voucher if one would arise under the latter regime. But a modified version of Proposition 4 can be applied to the empirical question:

Proposition 4B: Assume the superintendent chooses public school in the regime with no voucher and then optimally chooses $g=g^{* *}$. Allowing the superintendent to then choose a voucher, a positive voucher would result if:

$$
\begin{gathered}
\mathrm{g}^{* *} \cdot \partial\left[1-\mathrm{F}\left(\mathrm{y}_{\mathrm{T}}\right)\right] / \partial \mathrm{v}>1-\mathrm{F}\left(\mathrm{y}_{\mathrm{T}}\right) \text { given } \mathrm{v}=0, \mathrm{y}_{\mathrm{T}}=\mathrm{y}_{\mathrm{T}}\left(\mathrm{t}, 0, \mathrm{~g}^{* *}\right) \text {, and } \\
\text { t satisfying } \mathrm{tY}=\mathrm{F}\left(\mathrm{y}_{\mathrm{T}}\right) \mathrm{g}^{* *} \text {. }
\end{gathered}
$$

If, also, the superintendent's optimization problem has a unique local optimum, then (9) is also a necessary condition. ${ }^{15}$

The proof closely parallels that of Proposition 4A and is provided in Appendix B. The intuitive interpretation of (9) is the same as (8). If we then examine an economy that has not

\footnotetext{
${ }^{15}$ It is interesting to note that if (9) is satisfied, the superintendent elected under the no voucher regime would not expect to get re-elected!
} 
considered a voucher, (9) has the potential to be assessed empirically as discussed in Section 5.1.

In the next section, we examine computationally how changes in the income distribution affect incentives to provide a voucher. The next two propositions help to guide this investigation. Consider the effects on equilibrium of a change in the income distribution that has all households y experience a proportional income change to ky, $k>0$. Thus, if $k>(<) 1$, the economy becomes richer (poorer). The baseline economy has $k=1$, and we refer to the generalized economy allowing $\mathrm{k} \neq 1$ as the k-economy.

Proposition 5. If $U(x, q)$ is homothetic, all results about the baseline economy apply to the $k$ economy for redefined consumption vector $\left(x_{k}, q_{k}\right) \equiv(k x, k q)$.

Proposition 5 is very powerful. If equilibrium exists (does not exist) for $k=1$, then it exists (does not exist) for all $k \neq 1$. Taking a case where equilibrium exists for $k=1$, the equilibrium values in the $\mathrm{k}$ economy satisfy: $\left(\mathrm{t}_{\mathrm{k}}^{*}, \mathrm{v}_{\mathrm{k}}^{*}, \mathrm{~g}_{\mathrm{k}}^{*}\right)=\left(\mathrm{t}^{*}, \mathrm{kv}^{*}, \mathrm{~kg}^{*}\right)$;

$\left(\mathrm{y}_{\mathrm{k}}^{\mathrm{w}}, \mathrm{y}_{\mathrm{Tk}}\right)=\left(\mathrm{ky}^{\mathrm{w}}, \mathrm{ky}_{\mathrm{T}}^{\mathrm{e}}\right)$; and consumption of household ky in the k-economy is equal to $(\mathrm{kx}, \mathrm{kq})$ for $(x, q)$ consumption of household $y$ in the baseline economy. For example, if household $y$ chooses private school in the baseline economy and consumes $(x, q)=((1-t) y-s, v+s)$, then household ky in the $k$ economy consumes $\left(x_{k}, q_{k}\right)=((1-t) k y-k s, k v+k s)$. Perhaps most importantly for our purposes, if there is no voucher in the baseline economy, then there will be no voucher in the k-economy. And, if there is a voucher in the baseline economy of $v$, then there will be a voucher in the k-economy of kv.

In addition to assuming homothetic preferences, if we also restrict attention to income distributions identified by their first two moments, then knowledge of the coefficient of variation of income, $c_{v}$, is sufficient to determine whether a voucher arises in equilibrium. The 
latter is an implication of the next proposition. Let $\mathrm{E}[\mathrm{y}]$ denote the mean of income and $\sigma_{\mathrm{y}}$ its standard deviation. We refer to distributions fully identified by their first two moments as $\mathrm{M}_{2}-$ identifed distributions. ${ }^{16}$ We have:

Proposition 6. If $U(x, q)$ is homothetic, then the k-equilibrium values can vary with a change in the income distribution only if $\mathrm{c}_{\mathrm{v}} \equiv \sigma_{\mathrm{y}} / \mathrm{E}[\mathrm{y}]$ varies for $\mathrm{M}_{2}$-identified income distributions.

The crux of the Proof of Proposition 6 is that income distribution changes that do not change $c_{v}$ are equivalent to changes in k. Such distributional changes "only" induce proportional changes in consumption variables. For an income distribution change to have non-proportional effects, including causing the introduction or revocation of a voucher, $c_{v}$ must change. We examine the effects of changes in $c_{v}$ in the computational analysis to which we now turn.

\section{Computational Analysis}

To perform the computational analysis, we must calibrate the household utility function and the income distribution. We assume the income distribution is lognormal. We use the U.S. household income distribution from 2008 in the baseline calibration, which had mean of $\$ 68,164$ and median of $\$ 50,112$. The implied mean and standard deviation of $\ln (\mathrm{y})$ are $\mu=$ 10.822 and $\sigma=.784$.

We adopt the CES utility function:

(9) $\quad U=\left[\beta q^{-\rho}+(1-\beta) x^{-\rho}\right]^{-1 / \rho}$.

We calibrate by choosing the two parameters of the utility function so that the equilibrium values of public school expenditure per household and the public school enrollment share match the empirical values in the U.S. for 2007-08. Public educational expenditure per household that school year was $\$ 5,066$. The public school enrollment share was .892 .

\footnotetext{
${ }^{16}$ Standard one- or two-parameter distributions are $\mathrm{M}_{2}$-identified. Examples are the lognormal, exponential, uniform, logistic, and beta distributions.
} 
Parameters that yield the above expenditure and public share in the equilibrium we find below are $\rho=35$ and $\beta=.0433$. The equilibrium values are summarized in Table $1 \mathrm{~A}$. Using (9), one finds that (A1) is satisfied whenever $\rho>0$. We find $(A 2)$ and $(A 7)$ are satisfied as well, so the calibration implies an ends-against-the-middle equilibrium.

The equilibrium tax rate is .066 . The income of the superintendent that is elected is $\$ 40,530$, and the income of the household indifferent between public and private school is $\$ 133,026$. Households with income above the latter send their children to private school and join households with income below the elected superintendent in supporting lower (t,g). They are opposed by the other half of middle-income households who send their children to public school while favoring higher $(t, g)$ in the ends-against-the-middle equilibrium. Figure 2 shows the vote in favor of the equilibrium policy relative to the policy preferred by every other potential candidate. This confirms that the superintendent's preferred policy is a Condorcet winner among all preferred policies, and Proposition 0 applies. The majority preferring the elected superintendent's policy increases continuously as the income of the alternative candidate moves in either direction, until a very high or low income candidate is reached. A household with very high income of $\$ 215,529$ would, if elected, send their child to private school and choose the $(t, v, g)=(0,0,0)$ policy vector (Proposition 1$)$. This discontinuity in policy preference is why there is also a discontinuity in vote against such a candidate seen in Figure 2. Crossing this income threshold, a discrete set of richer households switch to favoring the alternative candidate's preferred policy. ${ }^{17}$

\footnotetext{
${ }^{17}$ The continuous peak in those favoring the elected superintendent's policy at the lower end of the income of alternative candidates in Figure 2 is less interesting. As the income of the alternative candidate declines toward 0 , the preferred tax falls rapidly, which also increases sharply support of rich households for the alternative candidate. This effect eventually decreases opposition to alternative candidates. We provide more detail about preferences of and for alternatives candidates in the next example where a voucher arises.
} 
In the equilibrium calibrated to the U.S. income distribution, the majority-preferred voucher is zero. The $10.8 \%$ that attend private school deters the superintendent from providing a voucher. The inequality condition in (8) is not satisfied. Intuitively, the cost to the district of providing a voucher to households that choose private school with no voucher exceeds the benefits from the reduction in expenditure on $\mathrm{g}$ from the households that would be induced by a voucher to move from public to private school. As we show below, the model predicts no voucher if the population income distribution has the extent of heterogeneity in incomes reflected in the U.S., as also in states (California, Michigan) with state-level voucher proposals that have typically failed. ${ }^{18}$

Now we recalibrate the income distribution to match that in Douglas County, Colorado (DCC henceforth), where a voucher was recently unanimously approved by the locally elected school board. For DCC, the U. S. Census reports median and mean household income to be $\$ 99,522$ and $\$ 118,373$ respectively. With lognormally distributed income, the implied mean and standard deviation for $\ln (\mathrm{y})$ are $\mu=11.508$ and $\sigma=.589$. Note that $\mathrm{DCC}$ is richer and has lower variance income distribution than the U.S. distribution. We retain the utility function parameters from the U.S. calibration.

Table 1B reports equilibrium values for the DCC income distribution. The top row allows a voucher and the bottom row assumes vouchers are not allowed. Here a voucher equal to $\$ 1684$ arises in equilibrium if permitted. In the voucher equilibrium, both the incomes of the superintendent and the household indifferent to public versus private school decline relative to the respective incomes if no voucher is allowed. The proportion attending private school rises from $6.5 \%$ to $8 \%$ with a voucher allowed. The tax rate declines slightly and public expenditure

\footnotetext{
${ }^{18}$ We also calibrated to the California and Michigan income distributions and found the equilibrium voucher to be zero in both cases. We have chosen to use the U.S. income distribution in the baseline calibration in an effort to examine an "average" case.
} 
rises slightly. Thus, those that attend public schools and private schools with and without a voucher are better off in the voucher equilibrium, as well as those that switch by revealed preference. In addition to the Pareto improvement from a voucher, every household gains in school quality. ${ }^{19}$

Figure 3, analogous to Figure 2, shows the proportion favoring the elected superintendent (who has income of $\$ 88,371$ ), if matched against a candidate with any other income. The figure confirms the superintendent's preferred policy is a Condorcet winner and Proposition 0 applies. The panels of Figure 4 show the policy vectors that alternative households would select if elected. Households with income below about $\$ 282,245$ would send their child to public school if elected. For these households, their preferred policy would have increasing tax and public expenditure as income rises, as implied by (A1). The preferred voucher would be 0 as income rises until income of about $\$ 60,000$ is reached, and then rise up to over $\$ 6,000$ with income for this group. From (7b), the marginal value of providing the voucher is proportional to: $-\left[1-\mathrm{F}\left(\mathrm{y}_{\mathrm{T}}\right)+\left(\mathrm{g}^{*}-\mathrm{v}\right) \mathrm{f}\left(\mathrm{y}_{\mathrm{T}}\right) \frac{\partial \mathrm{y}_{\mathrm{T}}}{\partial \mathrm{v}}\right]$, where $\mathrm{g}^{*}$ is the preferred $\mathrm{g}$ of the household in power. As depicted in Figure 5, the proportion in public schools increases as $\mathrm{g}$ and $t$ increase with income of the household in power. This effect increases the marginal benefit of providing the voucher and the voucher increases.

Households with income above $\$ 282,245$ would send their child to private school if in power, and would choose the $(t, v, g)=(0,0,0)$ policy vector. This discontinuity in policy is again why there is also a discontinuity in the vote against such a candidate. Figure 6 shows the incomes of the voting coalitions that would favor or oppose alternative-income candidates if

\footnotetext{
${ }^{19}$ In some analyses of school policies, welfare gains based on the household utility function are associated with declines in educational quality and achievement. See, for example, some of the policy effects in Epple and Romano (1998). If the household utility function is really a reduced form that reflects borrowing constraints on financing education or if there are externalities from educational achievement, then it is important to examine effects on educational quality per se.
} 
matched against the elected superintendent. The left vertical line is drawn at the income of the elected superintendent $(\$ 88,371)$ and the right vertical line at the lowest income household who, if in power, would send their child to private school and choose the $(t, v, g)=(0,0,0)$ policy vector. The ends-against-the-middle property of the voting coalitions characterizes policies near the winning candidate's policy. To the left of the right vertical line, the upper locus in the figure follows the minimum income of the household that would send their child to private school if the alternative candidate were in power. Households with incomes below the elected superintendent would choose a lower $(t, v, g)$, but with positive $(t, g)$ and perhaps $v$ (see Figure 4$)$. These alternative candidates would be supported by a minority coalition of poor and rich voters (the "favor groups"), with the latter sending their children to private school. Households with incomes above the elected superintendent, but not too far above, would send their child to public school and choose higher $(t, v, g)$ if in power (see Figure 4 again). These candidates would be supported by a minority of households with middle incomes (the "favor group"), but with income higher than the elected superintendent and not high enough that they would send their child to private school. ${ }^{20}$ A very high income candidate who would choose $(t, v, g)=(0,0,0)$ would find support from only high income households, with incomes above $\$ 122,279$. This group includes all households who would also choose $(t, v, g)=(0,0,0)$ if in power, as well as some less wealthy households who would choose public provision if in power but prefer private provision to the elected superintendent's moderate $(t, g)$ values. ${ }^{21}$

\footnotetext{
${ }^{20}$ Those high income households that would send their child to private school if the alternative higherincome candidate is in power would receive an increased voucher, but they prefer the elected superintendent's policy due to the lower tax rate. The out-of-equilibrium analogue to Assumption (A7) holds for these households.

${ }^{21}$ Given that income is taxed, it is perhaps surprising how high a household's income must be $(\$ 282,245)$ before they would choose $(t, v, g)=(0,0,0)$ if in power. All households with income above the mean are taxed disproportionately for public provision. But we find the subsidy to public education from wealthy households that select private school has a strong effect on policy preferences.
} 
Why does the DCC income distribution lead to a voucher in equilibrium while no voucher arises for the U.S. income distribution? The DCC and U.S. distributions differ in two respects. Households in DCC are richer, have substantially higher mean income, but also have lower income heterogeneity (lower standard deviation). A lower standard of deviation of income increases the incentive to provide a voucher as illustrated in Figures 7 and 8 . In both these figures, we vary the standard deviation of income while holding the mean constant at the DCC level. Figure 7 shows the implied equilibrium voucher. A positive voucher arises and then increases as standard deviation of income declines.

Applying Proposition 4B, Figure 8 illustrates the tradeoff affecting the tax rate from marginally increasing the voucher from 0 . The marginal benefit $\left(M B=g^{* *} \cdot[\partial(1-F) / \partial v]\right)$ of increasing the voucher at $\mathrm{v}=0$ exceeds the marginal cost $(\mathrm{MC}=1-\mathrm{F})$ for relatively low standard deviations, implying a voucher in equilibrium. With low standard deviation, few students would attend private school in the no-voucher equilibrium, implying a low MC. A low standard deviation also implies a low $M B$, but it exceeds $M C .{ }^{22}$ When $M C=1-\mathrm{F}$ is low, the derivative of $1-$ $F$ with respect to $v$ is also low, which is why the $M B$ is also low. Equilibrium public educational expenditure with no voucher $\left(\mathrm{g}^{* *}\right)$ actually increases as the standard deviation of income declines (not shown in the figure), but this component of $\mathrm{MB}$ is outweighed by the derivative term. The key underlying intuition is that $\mathrm{g}^{* *}$ is satisfying to a larger set of relatively higher income households when the standard deviation of income is low so the proportion choosing private schools is small.

We have shown theoretically that the coefficient of variation $\left(c_{v}\right)$ is the relevant statistic for predicting a voucher with the restrictions on the utility function and income distribution that characterize our computational model. Figure 9 illustrates the same tradeoff as in Figure 8, but

\footnotetext{
${ }^{22}$ The difference between MB and MC at $\mathrm{v}=0$ does not predict the level of the voucher, which depends on the shape of these curves as $v$ is increased.
} 
as a function of $c_{v}$. With this characterization, we can show whether the model predicts a voucher for any region (assuming the same utility function and form of the income distribution). A lower $c_{v}$ predicts a voucher. As already conveyed, no voucher is predicted for the U.S. or for the states of Michigan and California, while a voucher is predicted for DCC. The values of $c_{v}$ for these regions are marked in Figure 9. Holding constant mean income in the U.S., the maximum standard deviation that would imply a voucher would be $\$ 47,485$, while the actual U.S. value is $\$ 62,846$.

If one examines national voucher programs outside of the U.S., the best match to the universal voucher examined here is Denmark's voucher program. ${ }^{23}$ "Vouchers" are provided directly to "independent schools," but students freely choose among them conditional on acceptance. ${ }^{24}$ The independent schools must follow curriculum limits but are free to admit applicants and charge additional tuition. The voucher covers about 80 to 85 percent of average school costs. Using 2004 household income data for Denmark from the Luxembourg Income Study (http://www.lisdatacenter.org/) and the preference calibration above, our model predicts: (i) an income tax of .0798; (ii) a voucher equal to 71.8 percent of public per student expenditure; and (iii) a 10.2 percent voucher take-up rate or private attendance rate. Empirical values for independent school attendance are 11.9 percent, the voucher covers about 80 percent of educational cost as noted, and educational expenditure in Denmark is about 8.8 percent of GNP (Justesen, 2002). Our model then does a fairly good job of predicting values for Denmark, a country with very low coefficient of variation.

\footnotetext{
${ }^{23}$ Other national voucher programs fail to conform to key elements of our model. The Chilean and Dutch programs, for example, provide the same funding level to independent voucher schools as they do to public schools.

${ }^{24}$ The source for the characteristics and values for the Denmark program is Justesen (2002), using the most recent school year, 1997-98, for which data is reported.
} 
While the model predicts a voucher in Douglas County, a salient shortcoming of the analysis is that a much smaller voucher is predicted than that passed. ${ }^{25}$ One can as well observe that numerous other school districts would have tight enough income distributions to predict vouchers in our model, counter to reality. ${ }^{26}$ We have already indicated that our model abstracts from factors that may influence voucher adoption. In Section 5.2 we discuss these in more detail.

\section{State Differences and Non-Fiscal Factors.}

5.1 State Differences. Following the analysis in Hoyt and Lee (1998), it is interesting to examine the differences across states with regard to whether the fiscal forces predict a voucher. From Proposition 4B again, the superintendent elected with no voucher permitted would prefer to enact a positive voucher if $\mathrm{g}^{* *} \cdot \partial\left[1-\mathrm{F}\left(\mathrm{y}_{\mathrm{T}}\right)\right] / \partial \mathrm{v}>1-\mathrm{F}\left(\mathrm{y}_{\mathrm{T}}\right)$. The impetus for such a policy change might be a court decision(s) that suggests legality of a voucher. We can observe $\mathrm{g}^{* *}$ and the no-voucher private attendance, which we denote $1-\mathrm{F}^{* *}$. The private school demand response to introducing a voucher $\left(\partial\left[1-\mathrm{F}\left(\mathrm{y}_{\mathrm{T}}\right)\right] / \partial \mathrm{v}\right)$ is not, however, observed. Nor can it be calculated without making assumptions about the household utility function and income distribution. The demand response might be estimated if one can observe exogenous variation in the fixed cost of attending private school. Variation in transportation costs, e.g., availability of efficient public transportation, might provide an avenue for estimation.

We do not pursue the estimation issues here. ${ }^{27}$ Instead, like Hoyt and Lee, we compute the minimum demand change by state that would be necessary to predict a voucher. Rather

\footnotetext{
${ }^{25}$ The predicted voucher is 18.3 percent of public expenditure, while the voucher passed in Douglas County equaled 75 percent of state funding or about 55 percent of total per student public funding. ${ }^{26}$ Other local voucher programs in the U.S. are targeted to low income households and thus fail to conform to the universal vouchers this paper studies.

${ }^{27}$ Using tuition variation to estimate the effects of a voucher change is challenging because tuition variation has both a price and income effect on demand, while voucher variation has only an income effect.
} 
than compute the minimum demand change that would predict any positive voucher, we compute the minimum elasticity, $\partial\left[1-F\left(y_{T}\right)\right] / \partial \ln v$, necessary to predict at least a $\$ 1,000$ voucher. ${ }^{28}$ Using (7b), this minimum value is approximated by: $\frac{1000 \cdot\left(1-\mathrm{F}^{* * *}\right)}{\mathrm{g}^{* *}-1000} \cdot{ }^{29}$ We compute the threshold elasticity necessary for at least a $\$ 1,000$ voucher since the analogue for any positive voucher would not be very meaningful if the equilibrium voucher were to be very small and so we can compare our findings to those of Hoyt and Lee. The threshold elasticity equals the minimum percentage increase in private school attendance in the population of students from a proportional voucher increase at $v=\$ 1,000$ that is necessary for a voucher of at least $\$ 1,000$.

Table 2 reports the empirical values used as inputs to the calculation, and the threshold elasticity for the 2007-08 school year. The threshold value varies significantly across the states, ranging from .27 in Wyoming to 2.28 in Louisiana. Of course, high public expenditure states with low private attendance require a relatively low elasticity to imply preference for a significant voucher. Hoyt and Lee compute for 1993-94 the minimum proportional decrease in public attendance needed for a tax saving from a $\$ 1,000$ voucher, which is comparable to our threshold elasticity if one divides our value by the proportion in public school. Comparing their findings to ours, two things stand out. The demand change needed for a tax saving (and thus political support) is generally substantially smaller for 2007-08 as compared to 1993-94. For example, the percentage reduction in public attendance needed for U.S. values they report is $2.3 \%$, while the first row in Table 2 implies the $2007-08$ value is $1.42 \%(=1.27 /[1-.107])$. Private school attendance percentages are quite stable from 1993-94 to 2007-08. The lower elasticity

\footnotetext{
${ }^{28}$ We calculate the "semi-elasticity," rather than the classic elasticity $\partial \ln \left[1-\mathrm{F}\left(\mathrm{y}_{\mathrm{T}}\right)\right] / \partial \ln \mathrm{v}$, since we observe $1-\mathrm{F}$ and thus can use this information.

${ }^{29}$ This is an approximation because we use the no-voucher empirical values, $\mathrm{g}^{* *}$ and $1-\mathrm{F}^{* *}$, while the exact value would require observation of these values if $v$ equaled $\$ 1,000$.
} 
values needed for a tax saving in 2007-08 are explained by higher expenditure in public schools. The second interesting comparison is that the relative demand changes needed across the states is quite stable. For example, Hoyt and Lee find the three states requiring the smallest demand changes for tax savings were Wyoming, Alaska, and Utah; and the three states requiring the largest changes were Louisiana, Mississippi, and Delaware. The comparable states in our analysis are, respectively, Wyoming, Alaska, and West Virginia; and Louisiana, Delaware, and Hawaii.

5.2 Non-Fiscal Factors. We now briefly consider a variety of non-fiscal factors that may be relevant to the political economy of vouchers. Voucher proponents frequently tout positive productivity effects from increased competition among schools for students that vouchers would induce. ${ }^{30}$ Empirical research on productivity effects faces difficult identification problems and the evidence is mixed. Key references are Hoxby (2000), who finds evidence indicating positive productivity effects from increased school choice, and Hsieh and Urquiola (2006), who find no productivity effects from the national voucher program in Chile. Chakrabarti (2008) provides evidence that the Milwaukee voucher improved public school performance. Of course, the presence (or expectation) of productivity effects implies stronger political support for vouchers.

Another common pro-voucher argument is that vouchers would promote school differentiation, permitting better matching of student preferences and needs to the provision of education. Religious orientation of schools provides a primary example. The Catholic Church regularly lobbies for passage of voucher programs. Alternative secular emphasis in curricula, e.g., emphasizing language study, is another example of school differentiation that vouchers

\footnotetext{
${ }^{30}$ Substitution of private schools for public schools would increase productivity if private schools are more efficient, but the more compelling argument is that competition would cause all schools to be more productive.
} 
might promote and likely influences preferences for them. Countering this is the belief of some that society would be more cohesive if students share the same educational emphasis.

A common criticism of vouchers derives from ability-related peer effects in education.

The argument is that private schools would cream skim voucher supported high ability students, while shunning lower ability students, this to the detriment of public sector schools (see, e.g., Epple and Romano, 1998). The finding above that a tight income distribution is needed to obtain vouchers in equilibrium may be reinforced, as cream skimming will then be less of a concern. ${ }^{31}$ A related issue is that vouchers would increase school segregation along racial, ethnic, and/or socioeconomic dimensions. Using data from the defeated 2000 referendum on providing a universal voucher in California (Proposition 38), Brunner, Imazeki, and Ross (2010) find stronger support for vouchers by whites in public schools with higher concentrations of non-white students.

In a Tiebout economy with multiple school districts, vouchers might affect housing values and household sorting, and thus the incentives to support them. Nechyba $(1999,2000)$ analyzes vouchers theoretically and computationally in a Tiebout economy. Nechyba shows that take up of a universal voucher would increase with residential sorting because richer households can then move and take advantage of lower housing prices - which per se would increase political support for not-too-large vouchers - but there are as well fiscal and price effects. Brunner and Imazeki (2008) provide evidence from the 2000 California referendum regarding conflicting effects of vouchers on cream skimming and housing values in a Tiebout economy.

Scale effects can be expected to influence take up and thus preferences for vouchers. In less densely populated areas, for example, private school options might be very limited or

\footnotetext{
${ }^{31}$ The more limited effects of cream skimming with relatively homogeneous public school students is an element in Altonji, Huang, and Taber (2010).
} 
more costly. Finally, legal restrictions are a deterrent to local voucher initiatives and their success. Legal restrictions might require that vouchers could be used only at non-sectarian schools. The universal voucher program adopted in 1999 in Florida was subsequently declared unconstitutional by the Florida Supreme Court for example, and the Douglas County program itself was halted by a state judge and is currently being litigated.

\section{Summary}

Building on the research of Ireland (1990), Rangazas (1995), and Hoyt and Lee (1998), we have analyzed provision of a voucher in a political equilibrium. Public support for not-toolarge vouchers is strong if the cross subsidy to public school expenditure from those switching to private schools outweighs the subsidy to those that attend private school without a voucher. The difficulty in finding political equilibrium to assess the latter logic lies in the multidimensionality of the policy vector, which leads to nonexistence of a Condorcet winner among all feasible policy vectors. We appeal to Besley and Coate's (1997) representative democracy model to resolve the existence problem, which requires policies that are implemented to be those actually preferred by the policy maker and implies existence in our parameterization. Assuming homothetic utility function and for standard two-parameter income distributions, a voucher is adopted in the political equilibrium if the coefficient of variation of income is sufficiently small. For income distributions with income heterogeneity as exhibited by the U.S. distribution, no voucher arises in equilibrium. For tighter income distributions, including some examples that have adopted vouchers, our model predicts a voucher.

We provide a complete characterization of equilibrium with endogenous voucher levels in the "standard" fiscal model. Whether or not a voucher arises, equilibrium has the ends- 
against-the-middle property, where a coalition of rich and poor prefer lower taxes and public expenditure balanced by middle-income households that prefer the opposite.

The model is very simple with just two goods, a numeraire and education quality equated to expenditure, and with households differing only by income. It is of interest to consider other factors that can be expected to affect preferences for vouchers, but we have purposely chosen to conduct the analysis in the context of the "standard model." In addition to being tractable, this simple model gets to the core issue of fiscal effects of vouchers.

\section{Appendix}

A. Representative Democracy Model with a Continuum of Types. This part of the appendix is largely an adaptation of Proposition 2 and Corollary 1 in Besley and Coate (1997) to the case of a continuum of types. Their central assumption is that the policy preference of every population member is known and, if a population member is elected, then that policy will be implemented. Their Corollary 1 states roughly that existence of a Condorcet winner among preferred policy vectors in the population implies single candidate equilibrium exists for sufficiently low cost of becoming a candidate, with the individual having the Condorcet winning policy vector the candidate (and winner). Besley and Coate assume an integer number of voters, any of whom can be a candidate. Our model assumes a continuum of voters and thus potential candidates, indexed by endowed income $y$, with continuous distribution $F(y)$ and density $f(y)$, the latter positive on the support of $y$. We make analogous assumptions about preferences and equilibrium as do $B C$. We next summarize those assumptions and introduce a bit more notation, and then report the results of interest. We provide an additional result about uniqueness of equilibrium, but under a strong modification to $B C^{\prime}$ s model. 
A population member has indirect utility function $V=V(p, y)$, where $p$ is a policy vector. In the voucher-model application, a voucher, income tax rate, and per student level of public expenditure arise in equilibrium, but the policy vector in the indirect utility function $\mathrm{V}$ is bivariate as one variable is eliminated by the government balanced-budget requirement. Let $p^{*}(y)$ denote the preferred policy choice of voter $y$, which we assume is unique. Let $P^{*}$ denote the set of $\mathrm{p}^{*}$ values; i.e., $\mathrm{P}^{*} \equiv\left\{\mathrm{p}^{*}(\mathrm{y}) \mid \mathrm{f}(\mathrm{y})>0\right\}$. The results regard the case where there is a Condorcet winner $\mathrm{p}^{\mathrm{w}}$ :

$p^{w}$ is a Condorcet winner if $p^{w} \in P^{*}$ and $V\left(p^{w}, y\right) \geq V(p, y)$ for at least one-half the measure of voters for all $p \in P^{*}$.

Let $\mathrm{y}^{\mathrm{w}}$ satisfy $\mathrm{p}^{\mathrm{w}}=\mathrm{p}^{*}\left(\mathrm{y}^{\mathrm{w}}\right)$. Income $\mathrm{y}^{\mathrm{w}}$ may or may not be unique though it is unique in the voucher application. However, we have multiple voters with income $\mathrm{y}^{\mathrm{w}}$, consistent with the notion that $f(y)$ is positive. Let $Y^{w}$ denote the set of $y^{w}$ values.

Equilibrium assumes voters first decide whether to become candidates, followed by voting. Any voter can become a candidate at 0 cost, and voters choose to be candidates or not simultaneously. Given the slate of candidates, assumed non-empty at the moment, voters simultaneously and costlessly vote by voting for one candidate, though any voter can abstain. If a voter is indifferent between candidates and votes, then the voter randomizes with equal probabilities among them. The candidate receiving the highest measure of votes is the winner and that candidate's preferred policy is implemented. If there is a tie among the highest vote getters, then a winner is selected among them with equal probabilities. If no candidate enters the race or if a positive measure of votes fails to materialize, then a relatively lousy policy $p^{0}$ is 
implemented, which is worse for everyone than a positive measure of policies $p \in \mathrm{P}^{*} .^{32}$ It is also assumed that voters never choose a weakly dominated strategy when voting.

Two preliminary results are:

Result 1: If two candidates enter from the set whose policies are preferred to $p^{0}$, then a candidate that is majority preferred will win.

Result 2: If one candidate enters from the set whose policies are preferred to $p^{0}$, then that candidate is elected.

Result 1 is implied by the assumption that voters never choose a weakly dominated strategy. Given that it is costless to vote, a voter is never worse off and sometimes better off voting for their preferred candidate if there are just two candidates from this set. ${ }^{33}$ As well, sincere voting is implied with two candidates. Result 1 and the sincerity implication are results in BC.

Result 2 follows since everyone prefers the election of any candidate from this set to the lousy default outcome. It is not an equilibrium for a zero measure of voters to vote.

The main result is as follows:

Result 3: Assuming a Condorcet winner among preferred policies: (i) a single candidate equilibrium having a candidate $\mathrm{y}^{\mathrm{w}}$ exists, with that candidate elected; and (ii) a single candidate equilibrium must have a $\mathrm{y}^{\mathrm{w}}$ elected.

Proof of Result 3: (i) If only a $y^{w}$ becomes a candidate, then that candidate will be elected by Result $2 .{ }^{34} \mathrm{~A} \mathrm{y}^{\mathrm{w}}$ becoming a singleton candidate is an equilibrium, since, by Result 1 , any $\mathrm{y} \notin \mathrm{Y}^{\mathrm{w}}$

\footnotetext{
${ }^{32}$ The notion is that a lack of leadership if no one is elected results in a worse policy than that advocated preferred by some potentially elected households (though this assumption is becoming increasingly difficult to defend). Note, too, that BC assumed, if only one candidate enters, that candidate is automatically the winner (as that candidate could vote for himself if no one else votes). Since we require a positive measure of votes to win given the continuum, we must modify the assumption a bit.

${ }^{33}$ If the two candidates are equally preferred by everyone, then everyone still votes in equilibrium to avoid the possibility that no one votes and the lousy default policy arises.

${ }^{34}$ The $y^{w}$ candidate must have a policy in the set majority preferred to $p^{0}$, since $p^{w}$ is majority preferred in $P^{*}$.
} 
would not be elected and then gains nothing by also entering; nor would another $\mathrm{y}^{\mathrm{w}}$ entering gain since his preferred policy arises anyway. (ii) It is not an equilibrium for any $\mathrm{y} \notin \mathrm{Y}^{\mathrm{w}}$ to be the only entrant, since, by Result 1 , a $\mathrm{y}^{\mathrm{w}}$ would enter and win the election. We emphasize that Result 3 is a simple adaptation of BC's Corollary 1.

We can modify the $\mathrm{BC}$ model to generate uniqueness of equilibrium with equilibrium policy $\mathrm{p}^{\mathrm{w}}$. Assume two parties that simultaneously offer their party's candidacy to any voter. Only party candidates run. Once the slate is set, voters simultaneously vote as above. Preferences are as above, in particular party affiliation of a candidate does not affect preferences. Such a political process might arise if running for election is prohibitively costly for a non-affiliated candidate, while the party bears all running costs from exogenous funds for their affiliated candidate. A party wants to win the election. Under these assumptions and assuming a Condorcet winner:

Result $4::^{35}$ Equilibrium has each party offer their candidacy to $a y^{w}$, at least one accept the offer, and resulting policy $\mathrm{p}^{\mathrm{w}}$.

Obviously, the parties offer a candidacy to $a y^{w}$. At least one accepts the candidacy offer to avoid the default policy if neither runs. Whether one or both potential candidates run, voting equilibrium obviously implies that $\mathrm{p}^{\mathrm{w}}$ is implemented.

B. Proofs and Technical Analysis.

Proof of Proposition 1. Suppose, first, that the superintendent's income exceeds the mean. Consider the choice of $g$. If $g<v$, then no one chooses public school, and $v=t Y$. Setting $g=v$ also implies $v=t Y$. Setting $g>v$ is suboptimal, since this would drain funds from finance of the voucher and the superintendent cares not about the quality of public education. In any potentially optimal case (i.e., with $\mathrm{g} \leq \mathrm{v}$ ), the superintendent's preferred policy then satisfies:

\footnotetext{
${ }^{35}$ Jackson, Mathevet, and Mattes (2007) provide a similar result. See their Propositions 1 and 2.
} 
$\mathrm{U}^{\mathrm{R}}=\operatorname{Max}_{\mathrm{t} \geq 0, \mathrm{~s} \geq 0} \mathrm{U}(\mathrm{y}(1-\mathrm{t})-\mathrm{s}, \mathrm{tY}+\mathrm{s})$. The latter has solution $\mathrm{t}=0$ since the tax price of financing education with a voucher exceeds 1 . In turn, g must equal 0 . Now suppose the superintendent has income less than or equal to the mean. We show that such a superintendent prefers the public alternative, a contradiction. By the same argument as for a superintendent with income above the mean, the optimal policy would solve:

$\mathrm{U}^{\mathrm{R}}=\operatorname{Max}_{\mathrm{t} \geq 0, \mathrm{~s} \geq 0} \mathrm{U}(\mathrm{y}(1-\mathrm{t})-\mathrm{s}, \mathrm{tY}+\mathrm{s})$. In this case, $\mathrm{s}=0$ would be optimal since the superintendent here has tax price no higher than 1. But, by instead choosing public school and the same $t$ that solves the latter problem, the superintendent would obtain higher school quality g and thus higher utility provided any households would select private school. The result then follows from (A2).

Proof of Proposition 2. Since the superintendent's utility is given by $U\left(y(1-t), g^{*}\right)$, his objective in choosing $(t, v)$ is to minimize the equilibrium tax rate, which solves (4).

Proof of Proposition 3. The preferences in part (ii) for those in the public sector $\left(y<y_{T}^{e}\right)$ follows by Corollary 2 and (A1). The preference in part (ii) for those in the private sector $\left(y>y_{T}^{e}\right)$ follows by (A7), and (A2) implies some households do choose private education in equilibrium. Part (i) must then hold or a household with marginally different income would become a candidate and defeat household $\mathrm{y}^{\mathrm{w}}$ in the election.

Uniqueness of the Minimum of the Problem in (4) (To Complete the Proof of Proposition 4A). One can see by inspection of (4) that the minimum requires the constraint to hold with equality. Thus the minimum is the minimal $t$ that satisfies: $t Y=\left(1-F\left(y_{T}\right)\right) g+F\left(y_{T}\right) v$ for $v \geq 0$, where we drop the ${ }^{*}$ on $g$. Let $t^{m}(v)$ satisfy the latter equation. If and only if $t^{m}(v)$ is convex whenever $d t^{m} / d v=$ 0 is the local minimum unique. Straightforward calculation implies: 
(a1)

$$
\left.\frac{\mathrm{d}^{2} \mathrm{t}^{\mathrm{m}}}{d \mathrm{v}^{2}}\right|_{\frac{\mathrm{dt}^{\mathrm{m}}}{\mathrm{dv}}=0}=\frac{-2 \mathrm{f} \frac{\partial \mathrm{y}_{\mathrm{T}}}{\partial \mathrm{v}}+(\mathrm{g}-\mathrm{v})\left[\mathrm{f}^{\prime}\left(\frac{\partial \mathrm{y}_{\mathrm{T}}}{\partial \mathrm{v}}\right)^{2}+f \frac{\partial^{2} \mathrm{y}_{\mathrm{T}}}{\partial \mathrm{v}^{2}}\right]}{\mathrm{Y}+\mathrm{f} \frac{\partial \mathrm{y}_{\mathrm{T}}}{\partial \mathrm{t}}(\mathrm{v}-\mathrm{g})}
$$

From (7a), we know the denominator of the RHS of (a1) is positive (using that $\lambda<0$ as discussed in the text). The convexity condition then holds if the numerator is positive whenever $\mathrm{dt}^{\mathrm{m}} / \mathrm{dv}=$ 0. While we know the first term in the numerator (with sign) is positive, the rest of the numerator depends on the specifics of $f$ and the utility function.

Proof of Proposition 4B. By Proposition 2 any superintendent that selects public school solves the problem in (4). Moreover, while Proposition 2 assumes the superintendent's optimal choice of per student expenditure implying $\mathrm{g}^{* *}$ would not be optimal if a voucher is allowed and preferred, condition (9) implies a voucher is preferred at $\mathrm{g}=\mathrm{g}^{* *}$ and thus a voucher remains preferred after $\mathrm{g}$ is optimally adjusted. The necessity result follows since, absent (9), $\mathrm{g}^{* *}$ and $\mathrm{v}=$ 0 would be a local optimum and thus the global optimum.

Proof of Proposition 5. The primitives in the baseline model are the utility function $U(x, q), F(y)$, the prices of one for $(x, q)$, and the definition of equilibrium. Letting $y_{k} \equiv k y$, the economy with $F_{k}\left(y_{k}\right) \equiv F(y)$ and $U=U\left(x_{k}, q_{k}\right)$ is isomorphic to the economy $F(y)$ and $U(x, q)$. The latter follows since: (i) for all $y$, household $y$ 's preference ordering over $(x, q)$ and consumption possibilities are the same as household $\mathrm{y}_{\mathrm{k}}{ }^{\prime}$ s preference ordering over $\left(\mathrm{x}_{\mathrm{k}}, \mathrm{q}_{\mathrm{k}}\right)$ and consumption possibilities by the definition of homotheticity (see e.g., Mas-Colell, Whinston, and Green, 1995, Definition 3.B.6, p. 45); (ii) the income transformation implies $F_{k}\left(y_{k}\right) \equiv F(y)$ for all $y$; and (iii) prices and the definition of equilibrium are invariant to $k$.

Proof of Proposition 6. Let $\mathrm{E}[\mathrm{y}]$ and $\sigma_{\mathrm{y}}$ denote the mean and standard deviation of income for the $\mathrm{k}=1$ baseline economy. For $\mathrm{M}_{2}$-identifed income distributions, any changes in the income distribution correspond to changes in the mean and standard deviation of income. Any changes 
in the income distribution for which $c_{v}$ does not change imply there exists a post-change $k$ such that the new mean and standard deviation of income are: $k E[y]$ and $k \sigma_{y}$. Such a change in the income distribution is then equivalent to a change in $\mathrm{k}$ for which Proposition 5 implies the $\mathrm{k}$ equilibrium values are invariant. ${ }^{36}$ Thus, the k-equilibrium values can change only if the income distribution change implies a different value of $c_{v}$.

\footnotetext{
${ }^{36}$ By k-invariance, we mean the equilibrium values are always $(\mathrm{kx}, \mathrm{kq})$, etc., as in Proposition 5.
} 


\section{References}

Altonji, Joseph, Huang, Ching-I, and Christopher Taber, "Estimating the Cream Skimming Effect of Private School Vouchers on Public School Students," National Bureau of Economic Research Working Paper \#w16579, Dec. 2010.

Bearse, Peter, Buly Cardak, Gerhard Glomm, and B. Ravikumar, "Why Do Education Vouchers Fail?" 2009, working paper.

Besley, Timothy and Stephen Coate, "An Economic Model of Representative Democracy," Quarterly Journal of Economics, 112, February 1997, 85-114.

Brunner, Eric and Jennifer Imazeki, "Tiebout Choice and Universal School Vouchers," Journal of Urban Economics, 2008, 63, 253-279.

Brunner, Eric, Jennifer Imazeki, and Stephen L. Ross, "Universal Vouchers and Racial and Ethnic Segregation," Review of Economics and Statistics, 92, 2010, 912-927.

Brunner, Eric and Stephen L. Ross, "Is the Median Voter Decisive? Evidence from Referenda Voting Patterns," Journal of Public Economics, forthcoming.

Chakrabarti, Rajashri, "Can Increasing Private School Participation and Monetary Loss in a Voucher Program Affect Public School Performance? Evidence from Milwaukee," Journal of Public Economics, 92, 2008, 1371-1393.

Chen, Zhiqi and Edwin G. West, "Selective versus Universal Vouchers: Modeling median Voter Preferences in Education," American Economic Review, 90, December 2000, 1520-1534.

Epple, Dennis and Richard Romano, "Competition Between Private and Public Schools, Vouchers, and Peer Group Effects," American Economic Review, 88, 1998, 33-62.

, "Ends Against the Middle: Determining Public Service Provision when

there are Private Alternatives," Journal of Public Economics, 62, 1996a, 297-325.

February 1996b, 57-84.

"Public Provision of Private Goods," Journal of Political Economy, 104,

, "Educational Vouchers and Cream Skimming, International Economic

Review, 49, 2008, 1395-1435.

, "Economic Modeling and Analysis of Educational Vouchers," Annual

Review of Economics, 4, 2012, 159-184.

Epple, Dennis and Holger Sieg, "Estimating Equilibrium Models of Local Jurisdictions," Journal of

Political Economy, 107, 1999, 645-681. 
Hsieh, Chang-Tai and Miguel Urquiola, "The Effects of Generalized School Choice on Achievment and Stratification: Evidence from Chile's School Voucher Program," Journal of Public Economics, 90, 2006, 1477-1503.

Hoyt, William and Kangoh Lee, "Educational Vouchers, Welfare Effects, and Voting," Journal of Public Economics, 69, 1998, 211-228.

Hoxby, Carloine, "Does Competition Among Public Schools Benefit Students and Taxpayers?" American Economic Review, 90, 2000, 1209-1238.

Ireland, Norman, "The Mix of Social and Private Provision of Goods and Services, Journal of Public Economics, 43, 1990, 201-219.

Jackson, Matthew, Laurent Mathevet, and Kyle Mattes, "Nomination Processes and Policy Outcomes," Quarterly Journal of Political Science, 2, 2007, 67-94.

Kenny, Lawrence, "The Collective Allocation of Commodities in a Democratic Society," Public Choice, 33, 1978, 117-120.

Mas-Colell, Andreu, Michael D. Whinston, and Jerry R. Green, Microeconomic Theory, 1995, Oxford University Press, New York, New York.

McMillan, Robert, "Erratum to Competition, Incentives and Public School Productivity," Journal of Public Economics, 89, 2005, 1133-1154.

Nechyba, Thomas, "School Financed induced Migration Patterns: The Case of Private School Vouchers," Journal of Public Economic Theory, 1,1999, 5-50.

"Mobility, Targeting, and Private School Vouchers," American Economic Review, 90, 2000, 130-146.

Osborne, Martin, and Al Slivinski, "A Model of political Competition with Citizen Candidates," Quarterly Journal of Economics, 111, February 1996, 65-96.

Plott, Charles, "A Notion of Equilibrium and its Possibility under Majority Rule," American Economic Review, 57, September 1967, 787-806.

Rangazas, Peter, "Vouchers and Voting: An Initial Estimate Based on the Median Voter Model," Public Choice, 82, 1995, 261-279. 
Table 1A: Elements of Equilibrium for U.S.

\begin{tabular}{|c|c|c|c|c|c|c|}
\hline & $\begin{array}{c}\text { Superintendent } \\
\text { Income } \\
\left(\mathbf{y}^{\mathbf{w}}\right)\end{array}$ & $\begin{array}{c}\text { Income } \\
\text { Indifferent } \\
\text { Household }\left(\mathbf{y}_{\mathbf{T}}\right)\end{array}$ & $\begin{array}{c}\text { Percent } \\
\text { in } \\
\text { Public }\end{array}$ & $\begin{array}{c}\text { Public } \\
\text { Expend. } \\
(\mathbf{g})\end{array}$ & $\begin{array}{c}\text { Tax } \\
\text { Rate } \\
(\mathbf{t})\end{array}$ & $\begin{array}{c}\text { Voucher } \\
(\mathbf{v})\end{array}$ \\
\hline $\begin{array}{c}\text { Equilibrium } \\
\text { Allowing } \\
\text { Voucher }\end{array}$ & $\$ 40,530$ & $\$ 133,026$ & $89.2 \%$ & $\$ 5066$ & .066 & $\$ 0$ \\
\hline
\end{tabular}

Table 1B: Elements of Equilibria for Douglas County

\begin{tabular}{|c|c|c|c|c|c|c|}
\hline & $\begin{array}{c}\text { Superintendent } \\
\text { Income } \\
\left(\mathbf{y}^{\mathbf{w}}\right)\end{array}$ & $\begin{array}{c}\text { Income } \\
\text { Indifferent } \\
\text { Household }\left(\mathbf{y}_{\mathbf{T}}\right)\end{array}$ & $\begin{array}{c}\text { Percent } \\
\text { in } \\
\text { Public }\end{array}$ & $\begin{array}{c}\text { Public } \\
\text { Expend. } \\
\mathbf{( g )}\end{array}$ & $\begin{array}{c}\text { Tax } \\
\text { Rate } \\
(\mathbf{t})\end{array}$ & $\begin{array}{c}\text { Voucher } \\
(\mathbf{v})\end{array}$ \\
\hline $\begin{array}{c}\text { Equilibrium } \\
\text { Allowing } \\
\text { Voucher }\end{array}$ & $\$ 88,371$ & $\$ 227,726$ & $92.0 \%$ & $\$ 9203$ & .0726 & $\$ 1,684$ \\
\hline $\begin{array}{c}\text { Equilibrium } \\
\text { Not Allowing } \\
\text { Voucher }\end{array}$ & $\$ 90,418$ & $\$ 243,142$ & $93.5 \%$ & $\$ 9199$ & .0727 & - \\
\hline
\end{tabular}


Table 2: Minimum Increase in Private School Attendance for Adoption of Voucher Exceeding \$1,000 (2007-08) ${ }^{*}$

\begin{tabular}{|c|c|c|c|c|c|c|c|}
\hline Region & $\begin{array}{l}\text { Public } \\
\text { Expend** }\end{array}$ & \multirow{2}{*}{$\begin{array}{l}\begin{array}{l}\text { Private } \\
\text { Prop }\end{array} \\
0.107\end{array}$} & \multirow{2}{*}{$\begin{array}{r}\begin{array}{c}\text { Min } \\
\text { Elasticity }\end{array} \\
1.27\end{array}$} & \multirow[t]{2}{*}{ Region } & $\begin{array}{l}\text { Public } \\
\text { Expend** }\end{array}$ & \multirow[t]{2}{*}{$\begin{array}{l}\text { Private } \\
\text { Prop } \\
\end{array}$} & \multirow[t]{2}{*}{$\begin{array}{c}\text { Min } \\
\text { Elasticity }\end{array}$} \\
\hline United States & $\$ \quad 9,456$ & & & & & & \\
\hline Alabama & 8,307 & 0.101 & 1.38 & Missouri & 8,760 & 0.120 & 1.55 \\
\hline Alaska & $\$ 12,683$ & 0.037 & 0.31 & Montana & 8,599 & 0.096 & 1.26 \\
\hline Arizona & $\$ \quad 6,907$ & 0.056 & 0.95 & Nebraska & 9,605 & 0.121 & 1.41 \\
\hline Arkansas & $\$ \quad 7,737$ & 0.077 & 1.15 & Nevada & 7,643 & 0.064 & 0.97 \\
\hline California & $\$ \quad 8,796$ & 0.100 & 1.28 & New Hampshire & $\$ 11,326$ & 0.135 & 1.31 \\
\hline Colorado & $\$ \quad 8,521$ & 0.073 & 0.97 & New Jersey & $\$ 16,919$ & 0.155 & 0.97 \\
\hline Connecticut & $\$ 13,961$ & 0.131 & 1.01 & New Mexico & $\$ \quad 8,028$ & 0.076 & 1.09 \\
\hline Delaware & $\$ 11,197$ & 0.206 & 2.02 & New York & $\$ 15,787$ & 0.159 & 1.08 \\
\hline Dist.of Columbia & $\$ 14,492$ & 0.222 & 1.65 & North Carolina & $\$ \quad 7,015$ & 0.076 & 1.26 \\
\hline Florida & $\$ \quad 8,301$ & 0.130 & 1.77 & North Dakota & 8,038 & 0.073 & 1.03 \\
\hline Georgia & $\$ \quad 8,939$ & 0.087 & 1.09 & Ohio & 9,587 & 0.116 & 1.36 \\
\hline Hawaii & $\$ 10,332$ & 0.172 & 1.84 & Oklahoma & $\$ \quad 6,777$ & 0.059 & 1.02 \\
\hline Idaho & $\$ \quad 6,266$ & 0.082 & 1.56 & Oregon & $\$ \quad 8,698$ & 0.103 & 1.34 \\
\hline Illinois & $\$ 9,539$ & 0.128 & 1.50 & Pennsylvania & $\$ 10,897$ & 0.154 & 1.56 \\
\hline Indiana & $\$ \quad 8,235$ & 0.103 & 1.42 & Rhode Island & $\$ 13,334$ & 0.163 & 1.32 \\
\hline lowa & $\$ \quad 8,795$ & 0.089 & 1.15 & South Carolina & 8,226 & 0.090 & 1.25 \\
\hline Kansas & $\$ \quad 9,115$ & 0.092 & 1.13 & South Dakota & 7,230 & 0.089 & 1.42 \\
\hline Kentucky & $\$ 7,793$ & 0.102 & 1.50 & Tennessee & $\$ \quad 6,999$ & 0.108 & 1.80 \\
\hline Louisiana & $\$ \quad 8,330$ & 0.167 & 2.28 & Texas & 7,512 & 0.059 & 0.90 \\
\hline Maine & $\$ 10,706$ & 0.099 & 1.02 & Utah & $\$ \quad 5,513$ & 0.036 & 0.80 \\
\hline Maryland & $\$ 12,533$ & 0.164 & 1.42 & Vermont & $\$ 13,514$ & 0.119 & 0.95 \\
\hline Massachusetts & $\$ 12,911$ & 0.137 & 1.15 & Virginia & $\$ 10,005$ & 0.104 & 1.15 \\
\hline Michigan & $\$ 9,288$ & 0.087 & 1.06 & Washington & 8,327 & 0.091 & 1.24 \\
\hline Minnesota & $\$ 9,466$ & 0.108 & 1.28 & West Virginia & 8,959 & 0.050 & 0.63 \\
\hline Mississippi & 6,616 & 0.101 & 1.80 & Wisconsin & $\$ 10,102$ & 0.137 & 1.50 \\
\hline & & & & Wyoming & $\$ 12,971$ & 0.033 & 0.27 \\
\hline
\end{tabular}

*Data from National Center Educational Statistics, 2011 Tables 193,182,36,67 for 07-08.

**Per student public expenditure is net of federal supplement. 


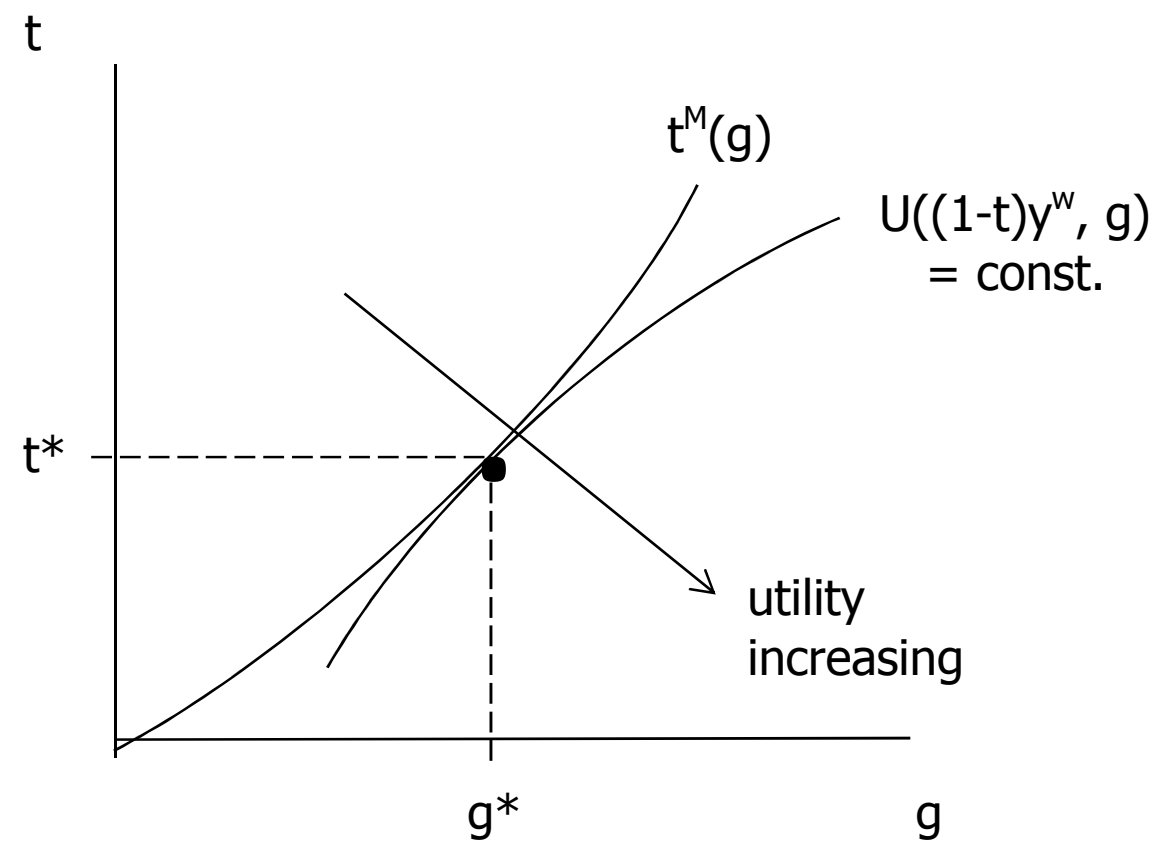

Figure 1 
Vote Favoring Proposal of Winning Candidate Against

Proposal of Every Other Potential Candidate

US Income Distribution

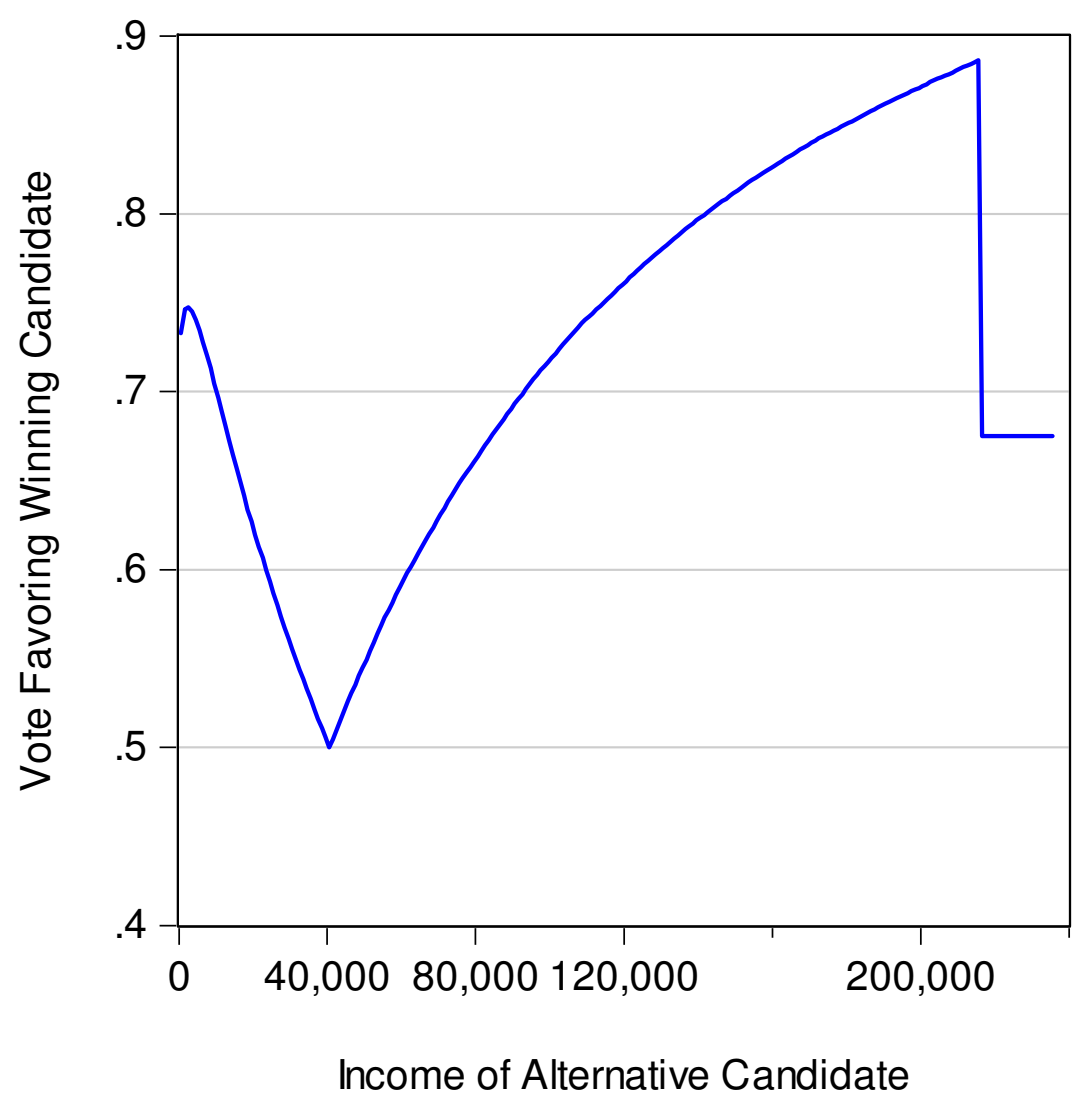

Figure 2 
Vote Favoring Proposal of Winning Candidate Against

Proposal of Every Other Potential Candidate

Douglas County, Colorado Income Distribution

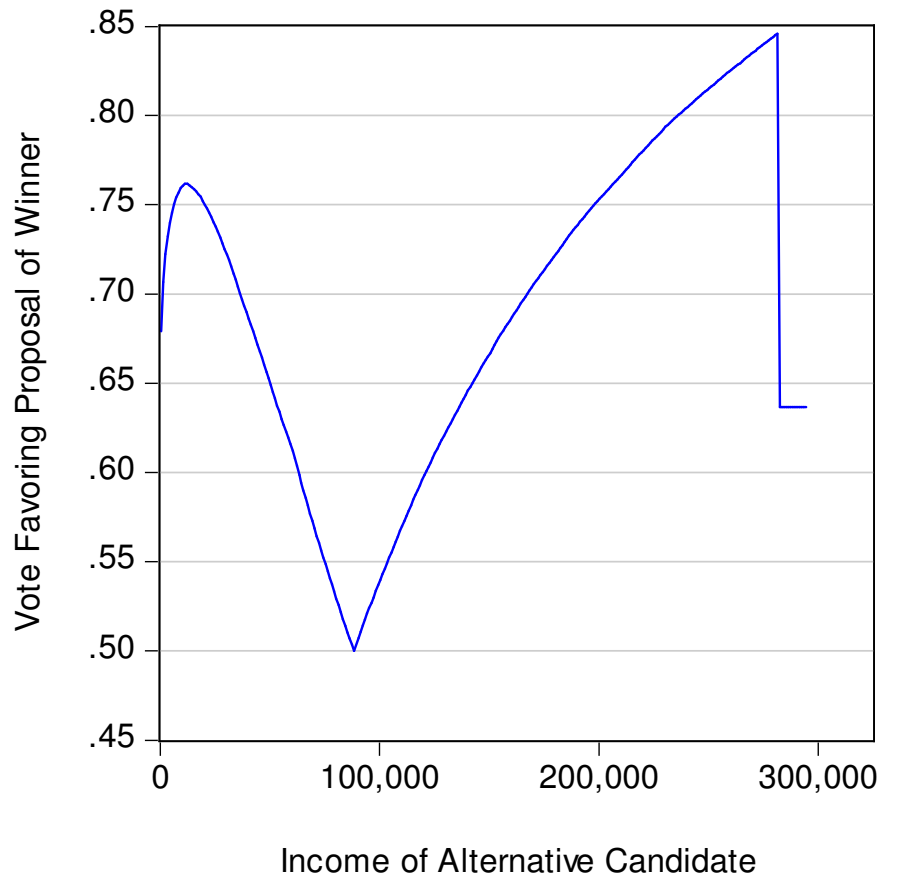

Figure 3 
Tax Rate Preferred by Each Potential Candidate

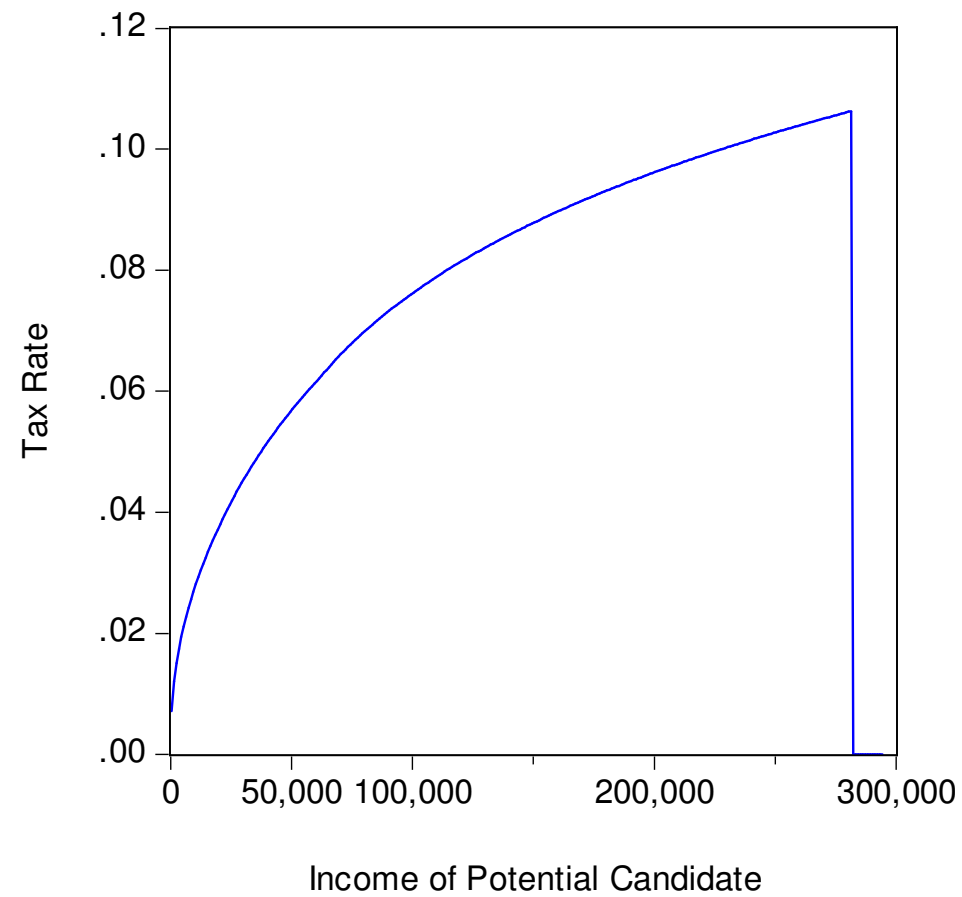

Public Expenditure and Voucher Preferred By Each Potential Candidate

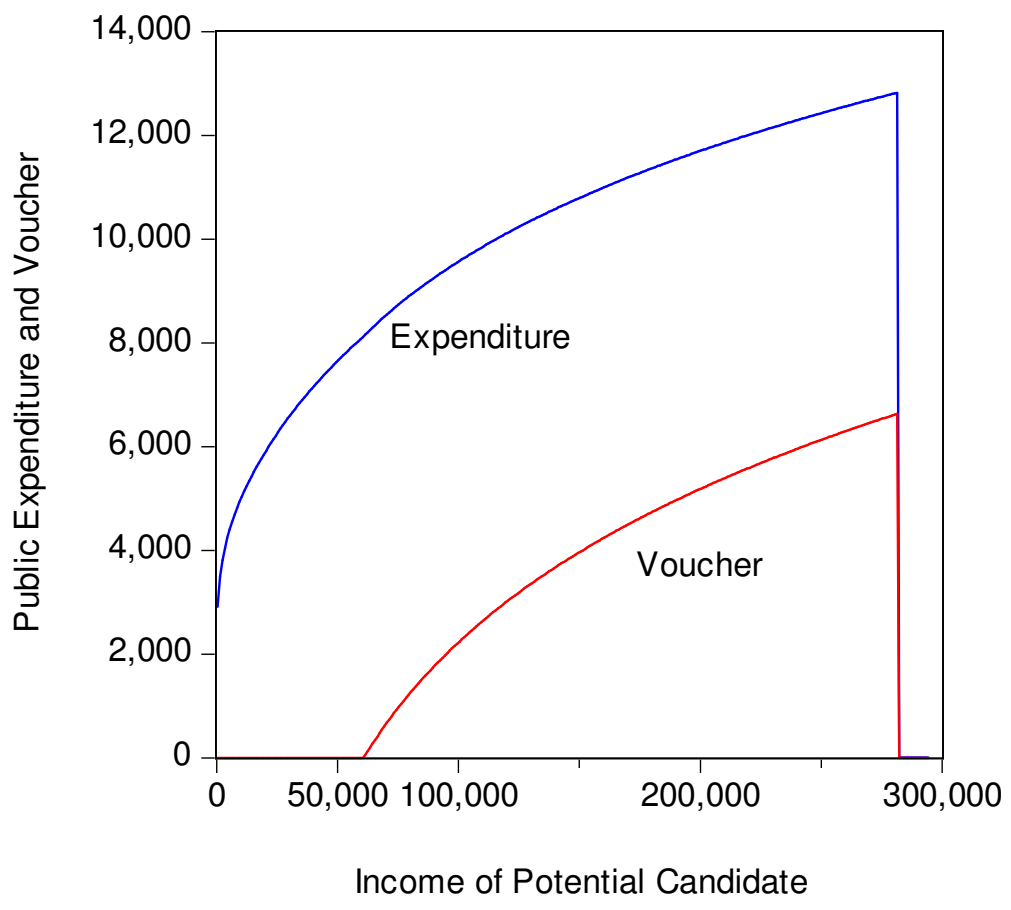

Figure 4 


\section{Proportion Attending Public School Under Proposal of Each Potential Candidate}

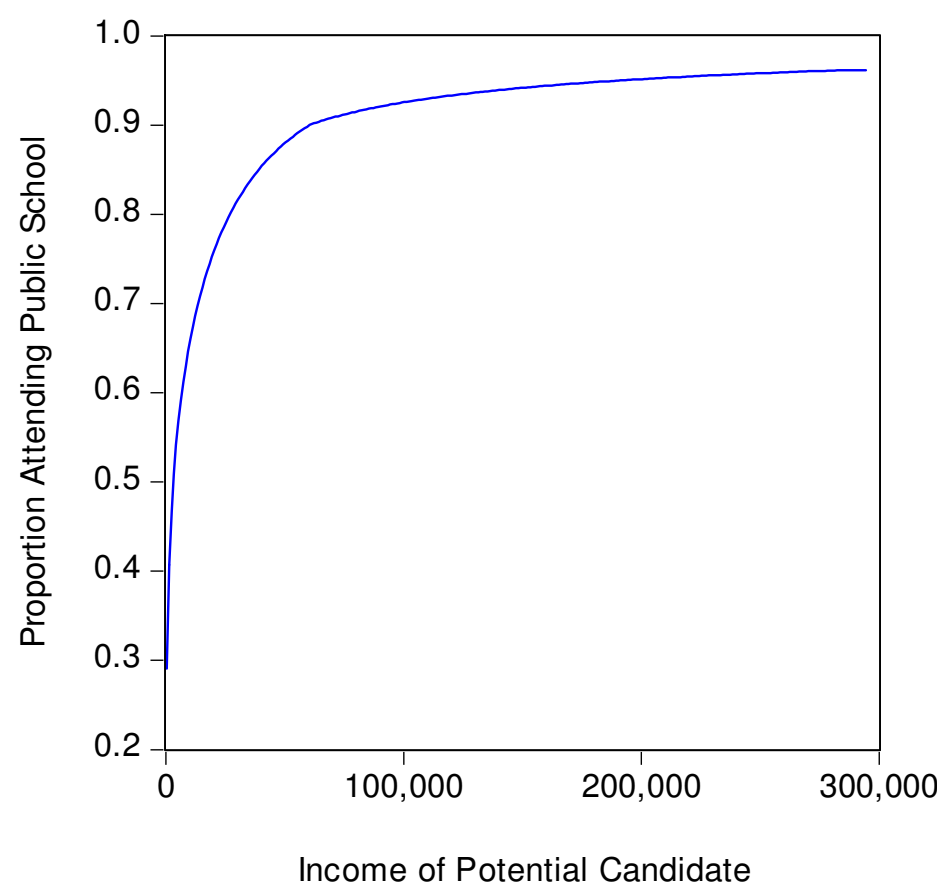

Figure 5 


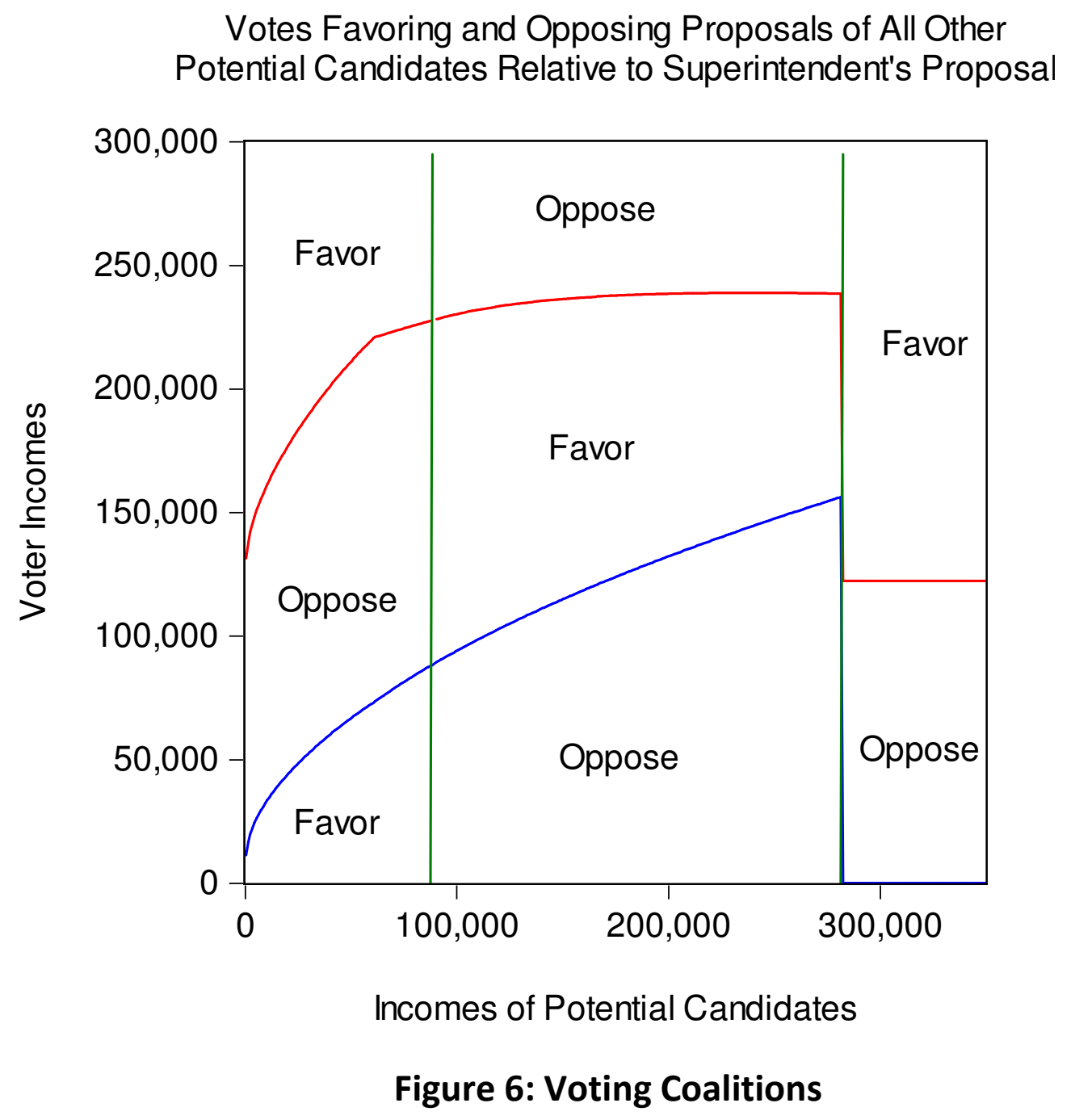




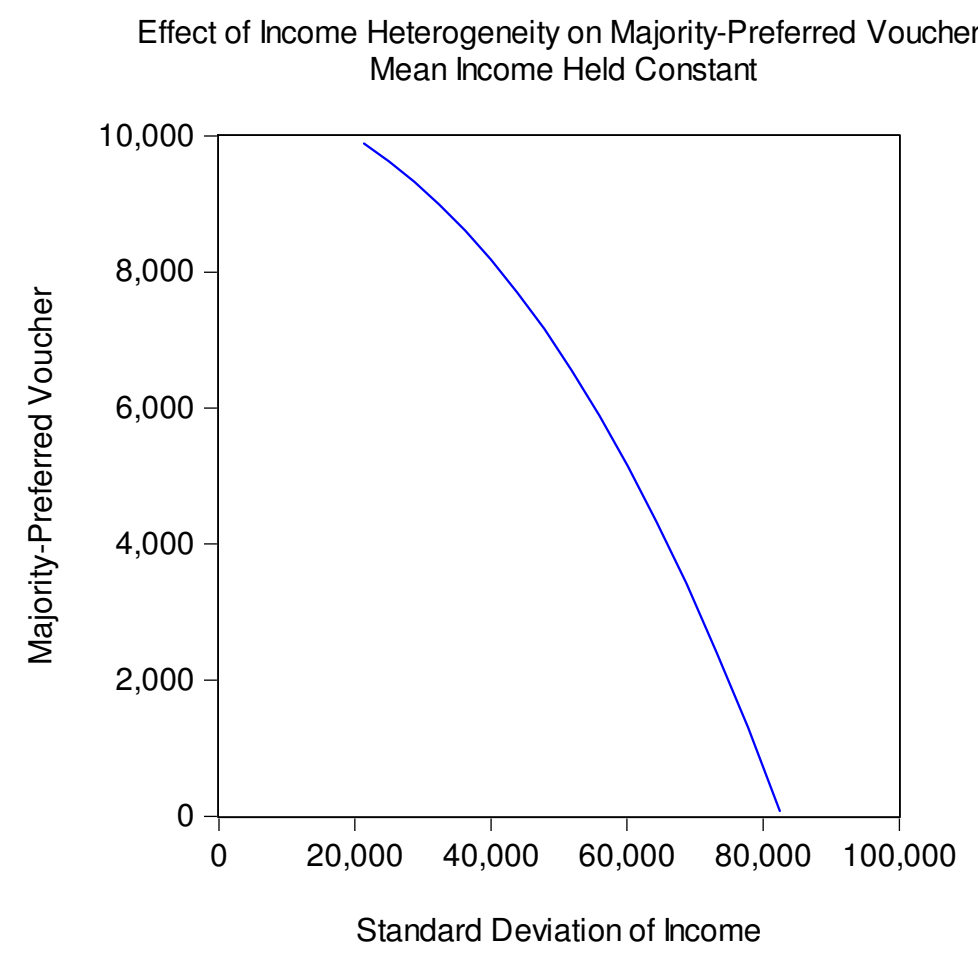

Figure 7 Effects Of A Mean-Preserving Increase In The Variance Of Incomes
On The Marginal Benefit and Marginal Cost Of Introducing A Voucher

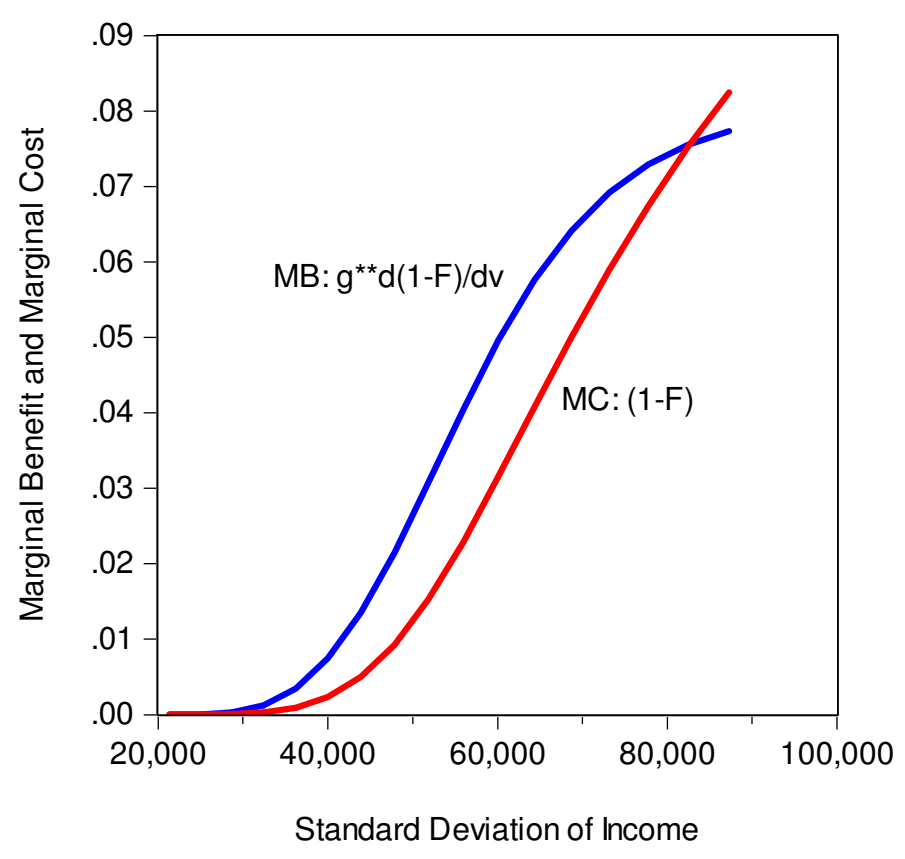

Figure 8 
Marginal Benefit and Marginal Cost of Introducing a Voucher As A Function of the Coefficient of Variation of Income

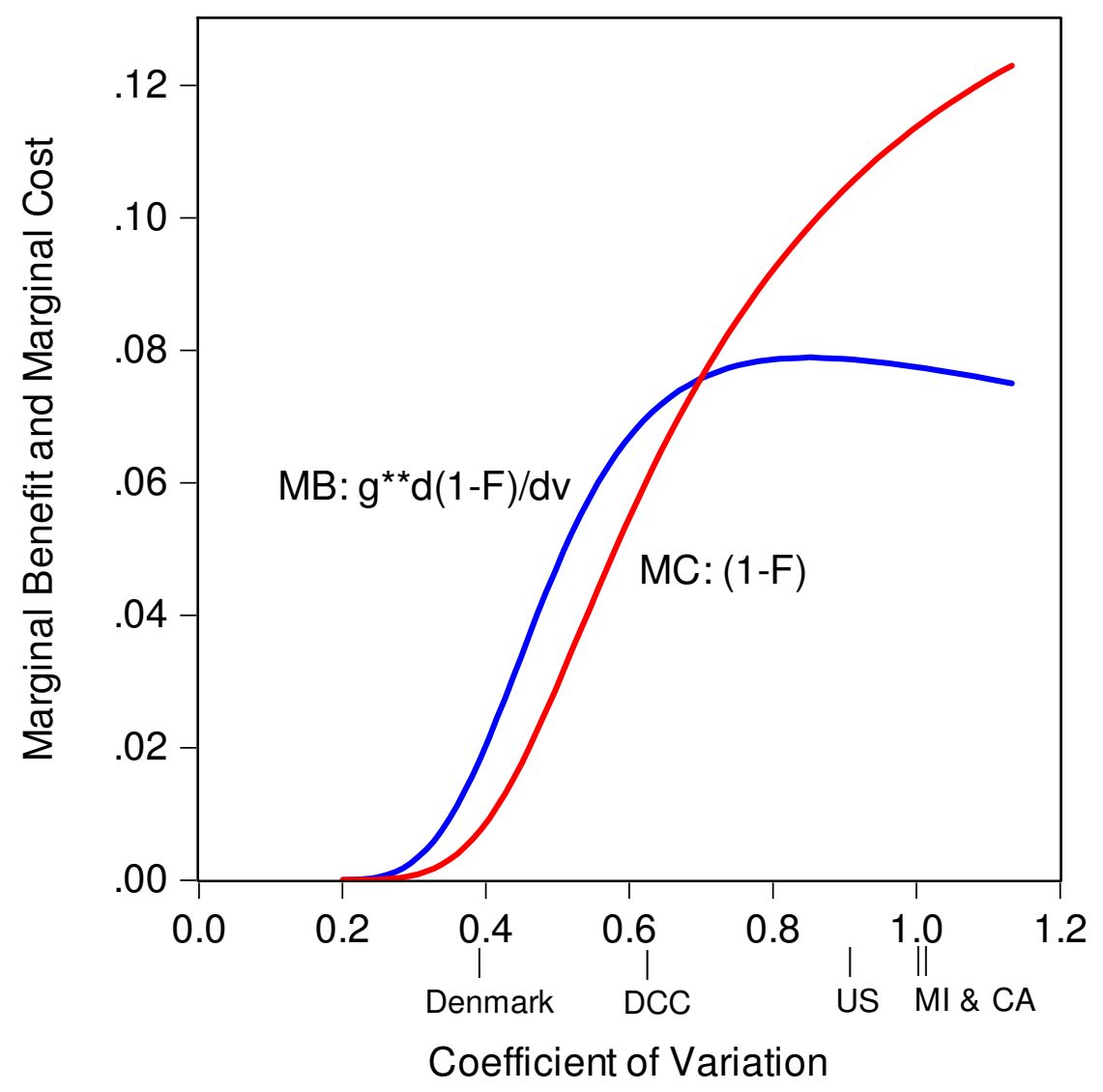

Figure 9 